\title{
"Salt Weathering" Distress on Concrete by Sulfates?
}

\author{
Zanqun Liu ${ }^{1,2.3}$, Geert De Schutter2, Dehua Deng1.3 and Zhiwu $\mathrm{Yu}^{1,3}$ \\ ${ }^{1}$ School of Civil Engineering, Central South University, Changsha, Hunan, \\ 2Magnel Laboratory for Concrete Research, Department of Structural Engineering, \\ Ghent University, Ghent, \\ ${ }^{3}$ National Engineering Laboratory for High Speed Railway Construction, \\ Changsha, Hunan, \\ 1,3P.R China \\ ${ }^{2}$ Belgium
}

\section{Introduction}

Salt weathering, also called salt crystallization or physical salt attack, is defined as the basic degradation mechanism that a porous material, such as stone and masonry, undergoes at and near the Earth's surface [1]. The parts of porous materials in contact with relatively dry air near the Earth's surface will be severely deteriorated but the parts buried in salts environment look sound.

Generally, the idea of sulfate attack on concrete means that a complex physiochemical process including several harmful productions formation through chemical reaction, such as ettringite and gypsum, following the crystal growth of these productions in cracks or pores resulting in concrete damage. However, another concept was given more and more attention that "salt weathering/physical salt attack" on concrete partially exposed to environment specially containing $\mathrm{Na}_{2} \mathrm{SO}_{4}$ or $\mathrm{MgSO}_{4}$. ACI (American Concrete Institute) created a new subcommittee, ACI 201-E (Salt Weathering/Physical Salt Attack) in 2009. In 2011, an ballot was performed to discuss if it is necessary to separate the "physical salt attack" from chapter 6 "sulfate attack" as chapter 8 for ACI 201.2R. There were also more and more reports discussing this topic [2-9]. It seems that this topic will be high interest and relevance for the concrete community.

Certainly, concrete is also a kind of porous material. When partially exposed to an environment containing salts (especially sodium sulfate), such as in the case of a foundation, dam, column, flatwork and tunnel, a large amount of efflorescence will appear on the surface of the concrete accompanied with a similar scaling manner as salt weathering distress on masonry, showing a freezing-and-thawing-like deterioration on the surface of concrete [2] (Fig. 1). Therefore, concrete technologists logically and involuntarily define this phenomenon as salt weathering distress on concrete or physical attack on concrete.

Apparently, it seems reasonable to attribute salt weathering to the decay of concrete partially exposed to sulfate environment. Concrete technologists subjectively accepted that 
salt weathering or salt crystallization cannot be avoided in concrete, because concrete is also a kind of porous material similar to stone. However, in effect, some field and indoor research results of "salt weathering" distress on concrete have shown a number of appearances opposite to the basic principles of salt weathering on porous materials. Therefore, it is necessary and imperative to present this problem to avoid further confusion.
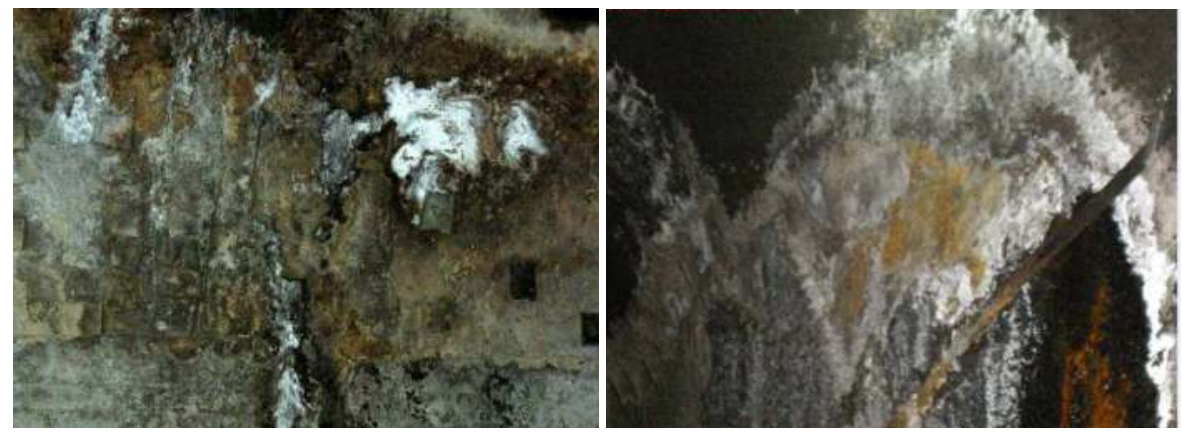

Fig. 1. Deterioration of railway tunnel (Southwestern Region, China)

This review paper includes three parts. First, the basic principles of salt weathering on porous materials are reviewed. Second, some field and indoor tests of "salt weathering" on concrete by sulfates are presented. Some appearances, which were generated by "salt weathering" on concrete but were opposite to the basic principles of salt weathering on porous materials, are analyzed in detail. Several points that need further study are presented in the third part.

\section{Salt weathering distress on porous materials}

\subsection{Salt crystallization in pore}

The work of Carl W. Correns on crystallization pressure is undoubtedly a milestone in the field of durability of porous materials [10], and the equation (Eq. (1)) exhibited in his paper written in 1949 for crystallization is broadly used and quoted.

$$
P=\frac{R T}{v} \ln \left(\frac{C}{C s}\right)
$$

Where $R$ is the ideal gas constant, $T$ is the absolute temperature, $v$ is the molar volume, $C$ is the concentration of solution, and $C s$ is the concentration of saturated solution. $C / C s$ is the supersaturation.

The above equation indicates that supersaturation is the key factor for crystallization. The supersaturation should be maintained during the process of salt crystallization. The crystal will grow until the supersaturation is consumed. He also pointed out that a thin layer/film of aqueous solution always remains between the crystal and the internal solid walls of the porous network. The thin layer allows the solute to diffuse from the pore solution to the crystal surface that is growing against the pore wall. If this thin layer did not exist, the crystal would go into contact with the pore wall, the growth would stop and no 
crystallization pressure would form [11]. Diffusion through this thin layer will equalize the concentration at the tip of the crystal and in the gap between the side of the crystal and the pore wall [12] [13]. The concentration and mobility of ions within this gap have a profound impact on the crystallization stress [14].

On the other hand, for a crystal, when the equilibrium is established between solution and crystal, the solubility product will satisfy:

$$
\gamma_{c l} \kappa_{c l}=\frac{R T}{v} \ln \left(\frac{C}{C s}\right)
$$

Where, $\gamma_{c l}$ is the crystal / liquid interfacial energy; $\kappa_{c l}$ is the surface curvature of crystal. Eq. (2) means two facts: a smaller spherical crystal is in equilibrium with a higher concentration than a larger flat crystal (equilibrium growth). The larger crystal (a relatively flat crystal) will grow and consume the supersaturation. Consequently, the smaller crystal will dissolve and the liberated solution will diffuse to the larger crystal (non-equilibrium growth) [14].

For equilibrium growth, a confined crystal can only exert stress if it is in contact with a pore solution that is supersaturated with respect to the unloaded face of the crystal [15]. The stress can be obtained by Eq. (3) [11]:

$$
\sigma_{W}=\gamma_{c l}\left(\kappa_{c l}^{C}-\kappa_{c l}^{E}\right)
$$

Where, $\kappa_{c l}^{E}$ is the curvature of the pore entrance (labeled point E), and $\kappa_{c l}^{C}$ is the curvature of other internal points (labeled point C) (Fig.2).

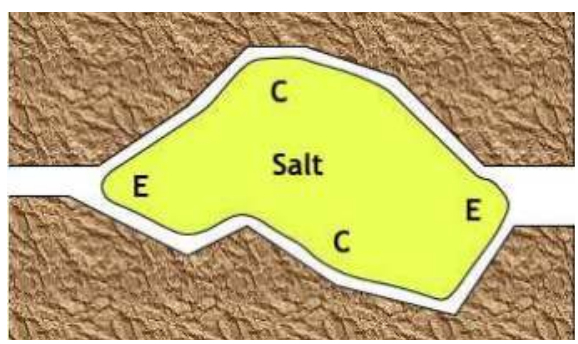

Fig. 2. Schematic of crystal of salt growing in a pore [14]

Because $\kappa_{c l}^{E}$ is less convex (positive) than $\kappa_{c l}^{C}$, the compressive strength is negative, but it creates a tensile stress in the hoop direction around the pore. This tensile stress is the destructive "crystallization pressure" A high equilibrium crystallization pressure requires a confined crystal in a pore of any geometry with a very small pore entrance [16]. Therefore, the stones with a bimodal pore size distribution are extremely susceptible to salt attack [17-19].

For non-equilibrium growth, all of the crystals in internal pores of a matrix with a distribution of pore sizes are unstable with respect to macroscopic crystals that nucleate in large voids. During the drying (evaporation) or in the presence of a sharp temperature gradient, the smaller crystals will dissolve and feed the growth of the larger one, reaching another equilibrium. During this equilibrium, a high transient stress can be produced (Eq. (4)) ${ }^{[14]}$. 


$$
\sigma_{W}=\frac{\gamma_{C L}}{r_{s}}-\frac{R_{g} T}{V_{m}} \ln \left(\frac{C}{C s}\right)
$$

Where, $r_{s}$ is the radius of the small pore entrance.

The duration and intensity of the transient crystallization pressure depend on three factors [14]: (1) the rate of supply of solute; (2) the rate of growth of crystal; (3) the rate of diffusion of solute to macro-pores. High evaporation can result in high supersaturation, and increase the growth of crystal and result in a high transient stress [14] [20], leading to severe damage by salt crystallization.

The supersaturation can be produced by cooling, evaporation and drying and wetting cycle. If the temperature dependence of the solubility of a salt is high, a drop of temperature can result in supersaturation. Supersaturation caused by evaporation always occurs when one face of the porous material is in contact with the solution and the other face is exposed to relatively dry conditions, i.e., the salt weathering process.

As to the relationship between strength and durability of porous materials, it always shows positive correlation [21-23]: porous materials with higher strength can suffer stronger salt crystallization distress.

\subsection{Characteristics of salt weathering distress}

In the process of salt weathering, efflorescence and sub-efflorescence will occur. Efflorescence always occurs on the surface of the material, and shows little or no damage. On the contrary, sub-efflorescence forms under the material surface and results in significant damage [24-26]. Some interesting studies showed that addition of ferrocianides $\left(\left[\mathrm{Fe}(\mathrm{CN})_{6}\right]^{4-}\right)$ can promote $\mathrm{NaCl}$ efflorescence growth as opposed to sub-efflorescence growth in porous stones, and minimize salt damage [27, 28].

Wick action is the transport of water (and any species it may contain) through a concrete (porous material) element face in contact with water to a drying face with less than $100 \%$ relative humidity of air [29]. The mechanism involves capillary sorption and evaporation.

During the process of wick action, if there is no evaporation, the solution level can increase through capillary rise in the concrete according to Eq. 5: [30]

$$
h=\frac{2 \gamma_{L V} \cdot \cos \theta}{\operatorname{rg} \rho}
$$

where $h$ is the height of capillary rise, $\gamma_{L V}$ is the liquid/vapor interfacial energy, $\theta$ is the contact angle, $r$ is the pore radius, $g$ is the gravitational acceleration, and $\rho$ is the density of the solution. In the case of water in concrete $\cos \theta \approx 1, \gamma_{L V}$ is $\sim 400 \mathrm{~mJ} \mathrm{~m}^{-2}$, and $r$ is the typically $10 \sim 100 \mathrm{~nm}$. Therefore, $h$ is about $1-10 \mathrm{~m}$. However, the pores will easily lose water due to evaporation. The pores of $10 \mathrm{um}$ will start to empty when the relative humidity is lower than $95 \%$. So, when the relative humidity is lower, $h$ will decrease. After some time, a state of equilibrium (wet-drying interface) may be reached. Then the rate of water entering the concrete by capillary sorption matches the rate of water leaving the opposite face of the concrete element by water vapour diffusion. 
If the water is containing salts, these salts cannot be carried by the vapour and therefore build up at this position. This concentration effect causes back-diffusion of salt away from the wet-dry interface. If the salts concentration near the wet-dry interface ever exceeds the solubility of the salt compounds present, precipitation is likely to occur [31-34]. The absorption-diffusion relationship can be described by the definition of the Peclet number [34]:

$$
P e \equiv \frac{h L}{\theta_{m} D_{c}}
$$

Where, $h\left(\mathrm{~m}^{3} \mathrm{~m}^{-2} \mathrm{~s}^{-1}\right)$ is the drying rate, $L(\mathrm{~m})$ the length of the sample, and $\theta_{m}\left(\mathrm{~m}^{3} \mathrm{~m}^{-3}\right)$ the maximum fluid content by capillary saturation. $D_{c}\left(\mathrm{~m}^{2} \mathrm{~s}^{-1}\right)$ is the diffusion coefficient of the ions in the moisture in the porous medium. For $\mathrm{Pe}<<1$ diffusion dominates and the ionprofiles will be uniform, whereas for $P e>>1$ absorption dominates and ions will be accumulated at the drying surface.

Y. T. Puyate et al discussed the chloride transport due to wick action in the concrete in detail [31-34]. One vital conclusion is that it was the vapour pressure of the solution and the relative humidity of air which control the position of the wet-dry interface [33]. The position of drywet interface locates in the inner of the concrete faced to a low relative humidity situation $(0 \%)(\mathrm{Pe}>>1)$, and a sharp peak of chloride concentration exceeding the saturation value occurs [34]. In contrast, in a high relative humidity condition $(78 \%)(\mathrm{Pe}<<1)$, the location of the interface is close to the concrete surface [31, 32]. Therefore, high evaporation can induce severe crystallization distress.

Nuclear magnetic resonance (NMR) is used to study the crystallization of sodium chloride due to wick action. Measuring the moisture and ion profile in a fired-clay brick cylinder ( $\varnothing$ $20 \times 45 \mathrm{~mm}$ ), an efflorescence pathway diagram is plotted $[35,36]$ as shown in Fig. 3 .

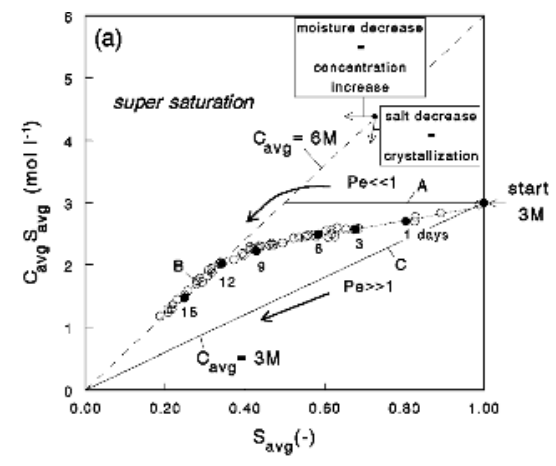

Fig. 3. Efflorescence pathway diagram [35]

According to this diagram (Fig.3), when $\mathrm{Pe}<<1$, i.e. very slow drying or high relative humidity, the ion profile remains homogeneous and for some time no crystallization will occur. The average $\mathrm{NaCl}$ concentration slowly increases until the complete sample has reached saturation, forming a high concentration pore solution zone. When Pe>>1, i.e. very fast drying or low relative humidity, ions are directly advected with the moisture to the top of the sample and a saturation peak will build up with a very small width. If the rate of 
crystallization is high enough, i.e. if there are enough nucleation sites at the top to form crystals, the average $\mathrm{NaCl}$ concentration of the solution in the sample itself will remain constant at nearly the initial concentration.

The mechanism of efflorescence is the crystals growing at a free surface: the crystals in the pores cannot be stable and will dissolve and diffuse towards the atmosphere (an infinite pore) (Eq.2). Because the crystals are in contact with the solution only in their bases, they cannot grow laterally but form long needles like whisker [14]. This is the reason why efflorescence is un-harmful for the porous materials. Sub-efflorescence precipitates when the evaporative flux is greater than the capillary flux in the porous materials where the solution is supplied by the capillary suction and evaporation [37].

In summary, the efflorescence and sub-efflorescence of salt weathering distress on the porous material can be schematically shown in Fig. 4.

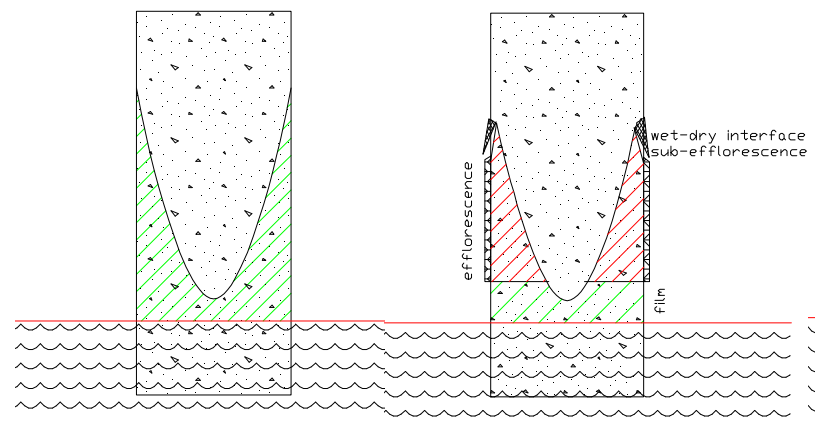

(a) (b)

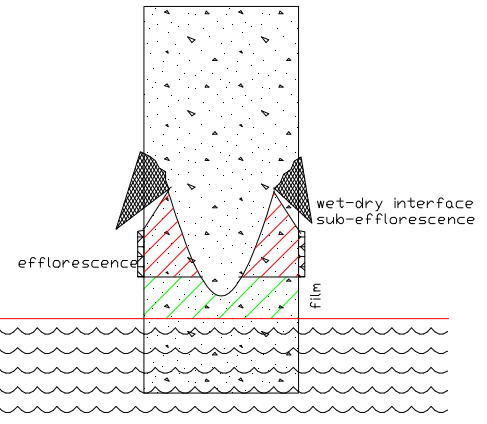

(c)

Fig. 4. Schematic of salt weathering distress on porous material.

(a) no evaporation condition, (b) low evaporation condition, (c) high evaporation condition

As we know, the capillary absorption just occurs in the interconnected pores between air and water. When a porous element is partially subjected to the sulfate solution under no evaporation condition, a pore solution zone will be formed as shown in Fig. 4(a). The solution cannot rise from the solution surface to the top of the element by capillary absorption due to few or no interconnected pores from the bottom to the top in a relatively long distance. The interconnected pores can form from the solution surface to the side surface of the element in a relatively short distance, resulting in the generation of capillary absorption.

Under a low evaporation condition, the wet-dry interface can occur in the tip of the pore solution zone, where the rate of evaporation is fast compared with the rate of solution rise, because solution rises into the bulk at a rate that decreases with height. At the same time the sulfate concentration of pore solution will slowly increase until the complete sample has reached saturation, forming a high concentration pore solution zone, where the efflorescence occurs. Near the solution a liquid film occurs on the surface of the element, where the rate of rise if fast compared with the evaporation and the sulfate concentration is close to the exposure solution [20]. In this case the deterioration due to salt crystallization is minor (as shown in Fig. 4 (b)). 
Under a low relative humidity condition, due to the high evaporation rate, the position of the wet-dry interface will move to the inner part of the element and closer to the bottom of the element, where a saturation peak will build up with a very small width, forming supersaturation, and resulting in sub-efflorescence and more severe deterioration. The breadth of efflorescence zone decreases and the average concentration of the pore solution will remain constant at nearly the initial concentration of exposure solution (as shown in Fig. 4 (c)).

\subsection{Crystallization of $\mathrm{Na}_{2} \mathrm{SO}_{4}$ and $\mathrm{MgSO}_{4}$}

Sodium sulfate is known to be a salt that causes the worst crystallization decay on porous materials and has become widely used in accelerated durability testing [38]. However, the sodium sulfate system is complicated, because under different conditions (temperature and relative humidity), it will form two stable phases (thenardite, $\mathrm{Na}_{2} \mathrm{SO}_{4}$ and mirabilite, $\mathrm{Na}_{2} \mathrm{SO}_{4} \cdot 10 \mathrm{H}_{2} \mathrm{O}$ ) or one metastable phase (heptahydrate, $\mathrm{Na}_{2} \mathrm{SO}_{4} \cdot 7 \mathrm{H}_{2} \mathrm{O}$ ) [12, 13] [39]. The metastable phase $\left(\mathrm{Na}_{2} \mathrm{SO}_{4} \cdot 7 \mathrm{H}_{2} \mathrm{O}\right)$ is formed during the rehydration of the anhydrous sodium sulfate phase $\left(\mathrm{Na}_{2} \mathrm{SO}_{4}\right)$ to the nucleation of mirabilite. Prior to mirabilite [12] [39], the crystallization pressure exerted by heptahydrate does not cause damage under the condition of the cooling experiments [36], and it can not be observed in building stone [13].

Regarding the damage caused by the crystallization of sodium sulfate, there are two views. One school thinks that the crystallization of thenardite is more destructive [40], because the crystallization of thenardite can generate higher pressure than mirabilite at the same supersaturation [41]. However, more and more experimental results support another school that the dissolution of thenardite producing a solution highly supersaturated with respect to mirabilite will cause the precipitation of mirabilite and result in the damage of porous materials [13] [38]. I.e. the transformation between thenardite and mirabilite can generate severe large crystallization pressure, resulting in porous materials damage.

The only naturally occurring members of the $\mathrm{MgSO}_{4} \mathrm{nH}_{2} \mathrm{O}$ series on Earth are epsomite $\left(\mathrm{MgSO}_{4} \cdot 7 \mathrm{H}_{2} \mathrm{O}, 51 \mathrm{wt} \%\right.$ water), hexahydrite $\left(\mathrm{MgSO}_{4} \cdot 6 \mathrm{H}_{2} \mathrm{O}, 47 \mathrm{wt} \%\right.$ water) and kieserite $\left(\mathrm{MgSO}_{4} \cdot \mathrm{H}_{2} \mathrm{O}, 13 \mathrm{wt} \%\right.$ water). In aqueous systems, epsomite is stable at $\mathrm{T}$ below $48.4^{\circ} \mathrm{C}$, hexahydrite is stable in the $\mathrm{T}$ range $48.4-68^{\circ} \mathrm{C}$, and kieserite is stable at $\mathrm{T}>68^{\circ} \mathrm{C}$ [42]. Thus, at the normal temperature, the crystallization of epsomite $\left(\mathrm{MgSO}_{4} \cdot 7 \mathrm{H}_{2} \mathrm{O}\right.$,) is the distress reason.

\subsection{Summary}

In summary, according to above review, the following basic principles of salt weathering on porous materials can be concluded:

1. Supersaturation is the key factor for salt crystallization. During the process of salt weathering the supersaturation must be maintained at a high level.

2. High evaporation results in the formation of strong sub-efflorescence, causing severe deterioration. Low evaporation results in weak crystallization distress but causes the formation of a pore solution zone with high concentration in the part of porous materials in contact with air. 


\section{Experimental studies of "salt weathering" on concrete}

\subsection{Long term field tests}

Since 1940, a long-term study of "salt weathering" on concrete was carried out by the Portland Cement Association (PCA) [43-45]. Thousands of concrete beams $(152 \times 152 \times 762 \mathrm{~mm})$ were laid horizontally to a depth of $75 \mathrm{~mm}$ in sulfate rich soils (about $5.6 \%$ sulfate ion by weight of soil) basins in Sacramento, California. About 10 to 12 wetting and drying cycles are carried out every year. As the experiment progressed, commercial salts were added into the soils to replenish losses through leakage, overflow, and possibly other undetermined causes. Water was added to the basins just before the soils began to show drying to maintain the soils saturated.

Three reports were published [43-45]: the first [43] provided the experimental results of initial set of beams resistance to sulfate attack between 1940 and 1949. The second [44] described the performance development of concrete beams for 5 years field exposure to soils containing sodium sulfate. The third [45] introduced the experimental results for 16 years exposure.

Some other five years field tests were carried out by Irassar and Di Maio [46]. Concrete cylinders with the size of $\varnothing 150 \times 300 \mathrm{~mm}$ were buried at half height in a soil containing approximately $1 \%$ sodium sulfate. There are several important common experimental observations of the above field experiences:

1. The parts of the beams above ground, regardless of their cement content, cement composition, mineral additions, surface treatments and type of coarse aggregates, were deteriorated severely. The parts of the beams under ground, however, show little or no deterioration;

2. Pozzolanic additions, such as fly ash, furnace slag or silica fume, play a negative role in the performance of concrete exposed to these conditions;

3. The water-to-cementitious material ratio $(\mathrm{W} / \mathrm{CM})$ is the primary factor affecting the durability and performance of concrete in contact with sulfate soils: applying a low $\mathrm{W} / \mathrm{CM}$ ratio results in a higher resistance to sulfate attack;

4. According to XRD, optical microscopy and SEM analysis, a large amount of chemical sulfate attack products, such as ettringite, gypsum and thaumasite, were identified in the upper part of concrete in contact with air. However, the samples for these tests were drilled with water [45, 46].

Concerning the deterioration mechanism, researchers attributed the failure of concrete to physical attack or salt crystallization. However, in effect the experimental results cannot be explained by salt weathering. Fig. 5 is the evolution of visual rating of the upper part of concrete in contact with air, obtained by Irassar and Di Maio [46].

In the test, the mix proportions of different mixes (the ratio of water : binder : sand : aggregate ) were almost the same with different dosages of fly ash, slag and natural pozzolan. From Fig.5, we can deduce some interesting observations:

1. Comparing concrete $\mathrm{H} 1$ and $\mathrm{H} 2$, the difference between them was the air content, namely $1.3 \%$ resp. $4.4 \%$. Thus, if the damage mechanism of the upper part of concrete was caused due to salt weathering, there would be a big difference in visual rating of these two concretes due to the different pore structures. However, after 5 years exposure the visual ratings were almost the same. 
2. As to the role of mineral additions, with the increase of dosage of fly ash and natural pozzolan, the concrete cylinders showed worse visual observation. This may be explained by the fact that salt crystallization in smaller pores can form higher crystallization stress due to the refinement of mineral additions. On the other hand, if we compare concrete $\mathrm{H} 3$ and $\mathrm{H} 5, \mathrm{H} 4$ and $\mathrm{H} 6$, we can find that with the same dosage the natural pozzolan ( $\mathrm{H} 5$ and $\mathrm{H} 6$ ) played a more negative role in concrete damage than fly ash ( $\mathrm{H} 3$ and $\mathrm{H} 4)$. However the compressive strength of reference cylinders of $\mathrm{H} 5$ and $\mathrm{H} 6$ were higher than $\mathrm{H} 3$ and $\mathrm{H} 4$ respectively. The tests of PCA also showed similar results. This appearance cannot be explained by the salt weathering.

3. Comparing the normal concrete and blended concrete, Irassar et al [46] attributed an increase in capillary suction height caused by the pore size refinement of mineral addition to the more severe deterioration of blended concrete. However, this is in conflict with the following observations. Following the explanation based on the height of capillary sorption, concrete with a low $\mathrm{W} / \mathrm{C}$ ratio should be more susceptible to salt weathering than with high $\mathrm{W} / \mathrm{C}$ ratio. In the paper by Nehdi and Hayek [47], we can find that the sorption height of mortar with W/C of 0.45 is higher than with W/C of 0.6. If the above explanation is right, the mortar with low W/C (0.45) should be more susceptible to damage than the mortar with high W/C (0.6). Obviously, this conclusion is opposite to the result of field tests.

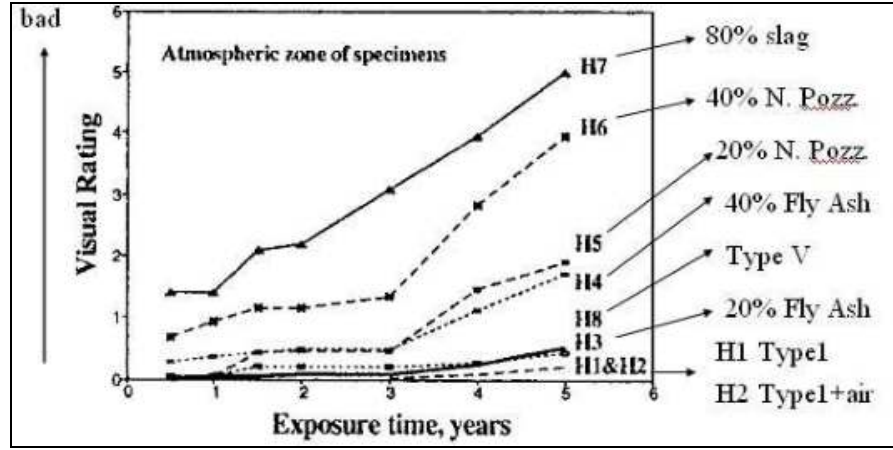

Fig. 5. Evolution of visual rating at the atmosphere part of concrete [46]

Besides, there are also some field cases, in which a wide variety of efflorescence salts (sodium sulfate, sodium chloride and magnesium sulfate) were routinely observed on the evaporating surface of the foundation concrete in South California [48, 49] However, the damage was not caused by salt crystallization. Much of the cement paste had lost its integrity, mainly as a result of the removal of portlandite, de-calcification of the calcium silicate phases and the ultimate replacement of calcium with magnesium in many of the cementitious compounds. Many reaction products, in particular magnesium silicate hydrate, brucite, Friedel's salt $\left(3 \mathrm{CaO} \cdot \mathrm{Al}_{2} \mathrm{O}_{3} \cdot \mathrm{CaCl}_{2} \cdot 10 \mathrm{H}_{2} \mathrm{O}\right)$, sodium carbonate and thaumasite were found at some depth within the concrete.

Another interesting case [50] concerns the slabs of Yongan Dam, which is in Keshi, Xinjiang, P.R. China, where the land is arid and rich in various kinds of salts, especially sulfate salts. The slabs were constructed in August - October 2003. The air temperature fluctuates significantly: the highest temperature is up to $37{ }^{\circ} \mathrm{C}$ and at night it is only $15-20^{\circ} \mathrm{C}$. Within 
this temperature range, the transformation between thenardite and mirabilite can occur. However, it was found that the slabs became gray and mushy throughout the thickness where they were in contact with groundwater due to thaumasite sulfate attack.

In summary, according to the above analysis the appearances of long term field tests did not show convincing evidences to support "salt weathering" causing the deterioration of concrete partially exposed to sodium sulfate environment.

\subsection{Indoor tests}

Rodriguez-Navarro and Doehne [26] studied the effect of evaporation on salt weathering distress on stone. After 30 days of exposure to a saturated sodium sulfate solution at constant $20{ }^{\circ} \mathrm{C}$, larger amounts of efflorescence and lower weight losses were observed when the crystallization took place at a relative humidity of $60 \%$ instead of at $30 \% \mathrm{RH}$. $\mathrm{H}$. Haynes and his coworkers [9] carried out some tests partially exposing the same concrete cylinders to $5 \% \mathrm{NaCl}$ and $\mathrm{Na}_{2} \mathrm{CO}_{3}$ solutions. Severe damage was observed for concrete cylinders, which were placed in constant environment at $20{ }^{\circ} \mathrm{C}$ and $54 \%$ relative humidity from day 28 to day 530, and then at $20{ }^{\circ} \mathrm{C}$ and $32 \% \mathrm{RH}$ from day 530 to day 1132. The specimens kept in a constant environment at $20{ }^{\circ} \mathrm{C}$ and $82 \%$ relative humidity from day 28 to day 1132 looked sound. These observations can be explained by the fact that a low relative humidity results in more evaporation, leading to sub-efflorescence [20] that forms deep in the material and results in significant damage ${ }^{[24,25]}$ as explained in the section 2.2.

However, contradictory observations can be found with respect to concrete exposed to sodium sulfate solution [51]. Two concrete specimens with the same mixture proportions were partially immersed in $10 \% \mathrm{Na}_{2} \mathrm{SO}_{4}$, solution. One specimen was placed at $80 \% \pm 5 \% \mathrm{RH}$ and the other was placed at $30 \% \pm 5 \%$. After 75 days of exposure to a constant temperature of $25{ }^{\circ} \mathrm{C}$, the specimens at $80 \% \mathrm{RH}$ showed signs of deterioration first over a very large area, starting from above the solution level. On the contrary, at $30 \% \mathrm{RH}$, the zone of deterioration was narrower and was situated at a certain distance above the solution level. In this case, the first sign of deterioration was a crack, not spalling (shown in Fig. 6).

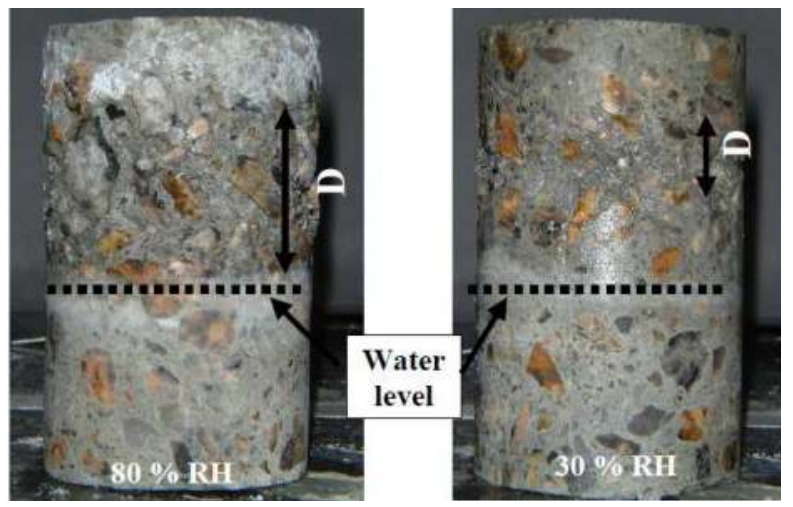

Fig. 6. Concrete cylinders exposed to sodium sulfate solution for 75 days [51] 
Similar results were also observed in the tests performed by H. Haynes and his coworkers [2]. Narrower spalling zone was found in case of concrete specimens exposed to constant environment at $20{ }^{\circ} \mathrm{C}$ and $54 \%$ relative humidity from day 28 to day 530 , and then at $20{ }^{\circ} \mathrm{C}$ and $32 \% \mathrm{RH}$ from day 530 to day 1132. Extensive spalling zone was found under constant environment at $20{ }^{\circ} \mathrm{C}$ and $82 \%$ relative humidity from day 28 to day 1132 . These tests will be discussed in detail as follow.

\subsubsection{H. Haynes tests ${ }^{[2,9]}$}

$\mathrm{H}$. Haynes and his coworkers performed very important and systemical tests about the salt weathering distress on concrete. In the two papers [2, 9], different ambient conditions were created within storage cabinets whose temperature and relative humidity were controlled. The concrete cylinders $(\varnothing 76 \times 145 \mathrm{~mm})$ were partially exposed to $5 \% \mathrm{Na}_{2} \mathrm{SO}_{4}, \mathrm{NaCO}_{3}$ and $\mathrm{NaCl}$ solutions. A partial submergence condition was achieved by wetting the specimen to a height of $25 \mathrm{~mm}$. At the height of $50 \mathrm{~mm}$, a plastic cover to the container functioned as a quasi-vapor retarder to minimize evaporation. The plastic cover did not touch the cylinder. Hence, within the region of 25 to $50 \mathrm{~mm}$ the cylinder was exposed to a moist environment. Above $50 \mathrm{~mm}$ ( 2 in.), the concrete was exposed to ambient environmental conditions. In the test program the author said that "the sulfate solution and tap water were replaced on a monthly basis; however, replacements for evaporation loss were provided at 2-week intervals. Much of the solution evaporated in the $40{ }^{\circ} \mathrm{C}$ and $31 \%$ relative humidity environment where, in general, at the end of 2 weeks, minor amounts of solution remained; and at times, no solution remained".

The tests were divided into two Phases for 3.1 years. The performance of concrete cylinders under five storage conditions was studied in detail, the exposures were:

Condition 1: steady at $20^{\circ} \mathrm{C}$ and $54 \%$ relative humidity from 28 to 530 days (Phase I), and then $20^{\circ} \mathrm{C}$ and $32 \%$ relative humidity from 530 to 1132 days (Phase II),

Condition 2: steady at $20^{\circ} \mathrm{C}$ and $82 \%$ relative humidity from 28 to 530 days (Phase I ), and then from 530 to 1132 days (Phase II),

Condition 3: $40^{\circ} \mathrm{C}$ and $74 \%$ relative humidity from 28 to 406 days (Phase I), and then $40^{\circ} \mathrm{C}$ and $31 \%$ relative humidity from 406 to 1132 days (Phase II),

Condition 4: 2-week cycles between $20^{\circ} \mathrm{C}$ and $54 \%$ relative humidity and $20^{\circ} \mathrm{C}$ and $82 \%$ relative humidity from 28 to 530 days (Phase I), and then 2-week cycles between $20^{\circ} \mathrm{C}$ and $31 \%$ relative humidity and $20^{\circ} \mathrm{C}$ and $82 \%$ relative humidity from 530 to 1132 days(Phase II),

Condition 5: exposed to 2-week cycles between $20^{\circ} \mathrm{C}$ and $82 \%$ relative humidity and $40^{\circ} \mathrm{C}$ and $74 \%$ relative humidity from 28 to 406 days(Phase I), and then 2-week cycles between $20^{\circ} \mathrm{C}$ and $82 \%$ relative humidity and $40^{\circ} \mathrm{C}$ and $31 \%$ relative humidity from 406 to 560 (847) days (Phase II).

The effects of $\mathrm{Na}_{2} \mathrm{SO}_{4}, \mathrm{Na}_{2} \mathrm{CO}_{3}$ and $\mathrm{NaCl}$ were compared. The visual observation was photographed, the average mass of scaling materials was collected, the species of concrete were identified by petrographic analysis, and chemical analysis was employed to study the ions distribution. According to the experimental results, they concluded that salt weathering 
plays the predominant role in concrete damage. However, there are a few questionable points about the relationship between the evidences and the conclusion based on the basic principles.

\subsubsection{Visual observation of concrete cylinders}

According to the photographs of visual observation at the end of exposure, we can find that:

1. When concrete cylinders were exposed to $\mathrm{Na}_{2} \mathrm{SO}_{4}$ solution, as abovementioned the concrete cylinders exposed to high relative humidity condition were deteriorated more severely than low relative humidity condition (as shown in Fig. 7).

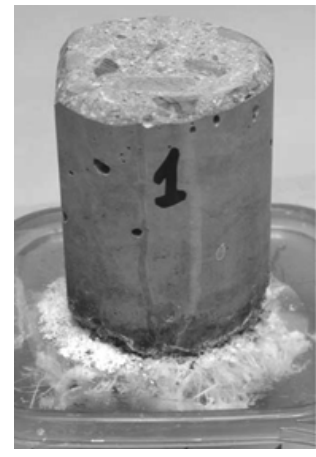

Condition 1

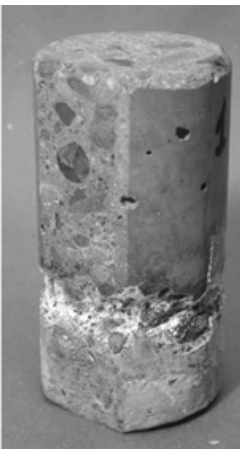

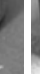

\section{.}

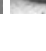

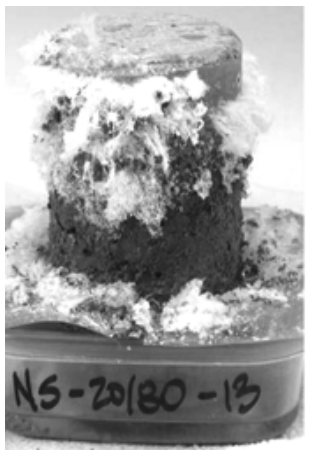

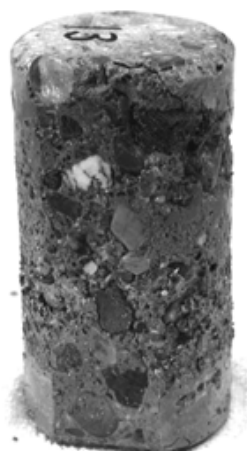

Condition 2

Fig. 7. Visual observation of concrete deterioration. Condition 1 : steady at $20^{\circ} \mathrm{C}$ and $54 \%$ relative humidity from 28 to 530 days (Phase I), and then $20^{\circ} \mathrm{C}$ and $32 \%$ relative humidity from 530 to 1132 days; Condition 2: steady at $20^{\circ} \mathrm{C}$ and $82 \%$ relative humidity from 28 to 530 days (Phase I ), and then from 530 to 1132 days [2]

Correspondingly, Fig. 8 shows the visual observation of concrete exposed to $\mathrm{Na}_{2} \mathrm{CO}_{3}$ and $\mathrm{NaCl}$ solutions under Condition 1 and Condition 2.
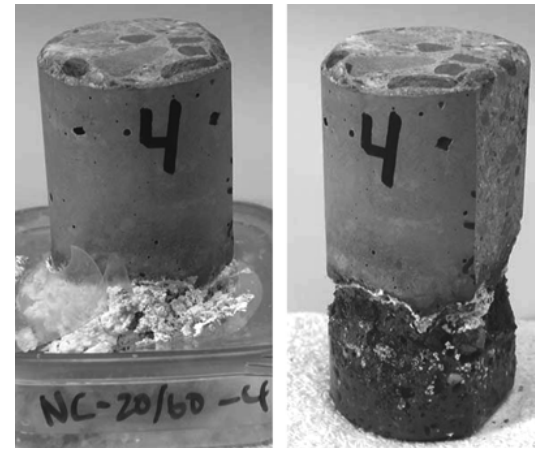

Condition 1
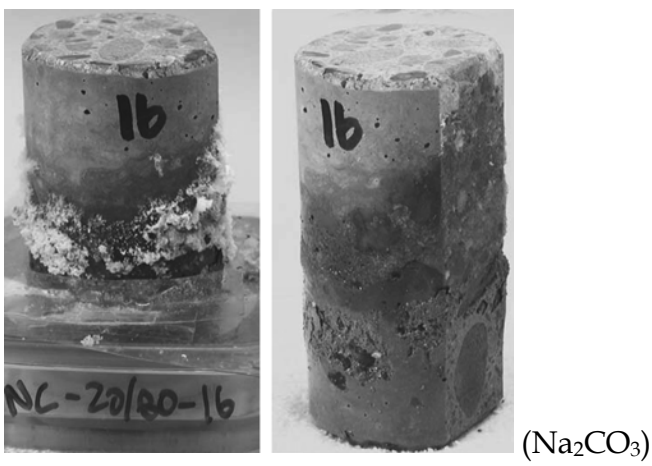

Condition 2 

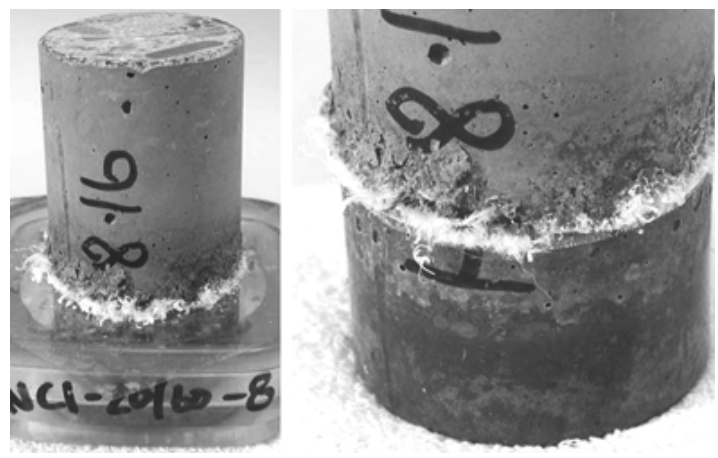

Condition 1
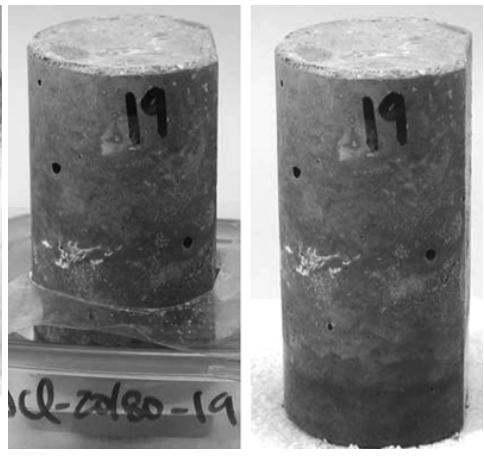

$(\mathrm{NaCl})$

Fig. 8. Visual observation of concrete deterioration exposed to $\mathrm{Na}_{2} \mathrm{CO}_{3}$ and $\mathrm{NaCl}$ solutions [9]

2. Under Condition $3\left(40^{\circ} \mathrm{C} / 74 \% \mathrm{RH}, 40^{\circ} \mathrm{C} / 31 \%\right)$, concrete showed the most significant scaling in the case of $\mathrm{NaCl}$, on the contrary, the concrete showed least scaling in the cases of $\mathrm{Na}_{2} \mathrm{CO}_{3}$ and $\mathrm{Na}_{2} \mathrm{SO}_{4}$ solutions. These appearances are contradictory because the concretes should show similar scaling manners due to the salt weathering in case of $\mathrm{Na}_{2} \mathrm{CO}_{3}$ and $\mathrm{NaCl}$ solutions. If the mechanism of concrete damage is also salt weathering in case of $\mathrm{Na}_{2} \mathrm{SO}_{4}$ solution, the concrete should also show similar scaling manners in $\mathrm{NaCl}$ solutions. If the mechanism of concrete damage is the chemical sulfate attack, the scaling manners of concrete cylinders by $\mathrm{Na}_{2} \mathrm{CO}_{3}$ and $\mathrm{Na}_{2} \mathrm{SO}_{4}$ solutions should show big difference. The possible reason of the above contradictory appearances may be the fast evaporation rate of $\mathrm{Na}_{2} \mathrm{CO}_{3}$ and $\mathrm{Na}_{2} \mathrm{SO}_{4}$ solutions. At high ambient temperature, $\mathrm{Na}_{2} \mathrm{CO}_{3}$ and $\mathrm{Na}_{2} \mathrm{SO}_{4}$ solutions would dry up soon, but some $\mathrm{NaCl}$ solution would remain. The tests under Condition 3 should be further studied to avoid the effect of evaporation of solution.

\subsubsection{Mass of scaling materials}

During Phase I from 28 days to 406 or 530 days: the worst damage occurred under Condition 5 (cycle $20^{\circ} \mathrm{C} / 82 \% \mathrm{RH}$ and $40^{\circ} \mathrm{C} / 70 \% \mathrm{RH}$ ) in the case of $\mathrm{Na}_{2} \mathrm{SO}_{4}$ solution (the mass of scaled material was about $16 \mathrm{~g}$ ). However, in the case of $\mathrm{Na}_{2} \mathrm{CO}_{3}$ solution the worst damage appeared under Condition $1\left(20^{\circ} \mathrm{C} / 54 \% \mathrm{RH}\right)$ (the mass of scaled material was just about 2.8g). This means that high $\mathrm{RH}$ can accelerate concrete damage by $\mathrm{Na}_{2} \mathrm{SO}_{4}$.

During Phase II from 406 or 530 days to the end of tests:

1. In the case of $\mathrm{Na}_{2} \mathrm{SO}_{4}$ solution the mass of scaled material under Condition $1\left(20^{\circ} \mathrm{C} / 32 \%\right.$ $\mathrm{RH})$ was less than Condition $2\left(20^{\circ} \mathrm{C} / 82 \% \mathrm{RH}\right)$. The opposite appearance was observed in case of $\mathrm{Na}_{2} \mathrm{CO}_{3}$ : the mass of scaled material was about $22 \mathrm{~g}$ under Condition $1\left(20^{\circ} \mathrm{C} / 32 \% \mathrm{RH}\right)$ and about $1 \mathrm{~g}$ under Condition $2\left(20^{\circ} \mathrm{C} / 82 \% \mathrm{RH}\right)$. Similar appearance also observed in the case of $\mathrm{NaCl}$ solution.

2. The mass of scaled material of concrete under Condition $1\left(20^{\circ} \mathrm{C} / 32 \% \mathrm{RH}\right)$ was less than Condition 4 (cycle $20^{\circ} \mathrm{C} / 82 \% \mathrm{RH}$ and $20^{\circ} \mathrm{C} / 31 \% \mathrm{RH}$ ) in case of $\mathrm{Na}_{2} \mathrm{SO}_{4}$. However, the mass of scaled material of concrete under Condition $1\left(20^{\circ} \mathrm{C} / 32 \% \mathrm{RH}\right)$ was almost the same as Condition $4\left(\right.$ cycle $20^{\circ} \mathrm{C} / 82 \% \mathrm{RH}$ and $20^{\circ} \mathrm{C} / 31 \% \mathrm{RH}$ ) in the case of $\mathrm{Na}_{2} \mathrm{CO}_{3}$. 
Corresponding to Phase I, this also means that high $\mathrm{RH}$ is in favor of the deterioration effect of $\mathrm{Na}_{2} \mathrm{SO}_{4}$ on concrete.

\subsubsection{Petrographic analysis}

According to petrographic analysis, abundant gypsum deposits were detected in large and small cracks, microcracks and voids near the surface of concrete. However, the authors presented two points to show that gypsum cannot result in concrete damage:

1. "Although trace amounts of gypsum were found near the outer surfaces, gypsum formation is a one-time occurrence, whereas crystallization of mirabilite and thenardite occurred repeatedly due to the biweekly cyclic changes in environmental conditions. Hence, the cycles of mirabilite and thenardite crystallization appear to be responsible for any significant expansion force". It is not clear why the authors thought that "gypsum formation is a one-time occurrence". According to above review, the solution can be drawn into the concrete continuously during wick action. In the presence of sulfate, gypsum crystals can continuously grow. Moreover, the authors pointed out that the $\mathrm{pH}$ value of the pore solution in the concrete should have been reduced due to carbonation, whereas for gypsum formation, the $\mathrm{pH}$ value of solution should be less than 11.9 [52].

2. "Despite the extensive alteration of the microstructure and the formation of gypsum, the concrete below the solution line was mostly intact with no mass loss, whereas there was substantial mass loss at the surface of the cylinder above the solution line. If gypsum did not cause scaling below the solution line, there is little reason to suspect that gypsum would cause scaling above the solution line. This indicated that salt crystallization alone, or in conjunction with gypsum, caused the scaling above the solution line. As salt crystallization by itself is known to damage rocks, the presence of gypsum is not necessary". This point seems reasonable, however, the authors did not give the quantitative analysis of gypsum. Because according to abovementioned wick action, a much higher concentration pore solution will be formed in the cylinder above the solution than under the solution, resulting in more severe sulfate attack and forming more gypsum.

\subsubsection{Chemical analysis}

Several cylinders were cut vertically to obtain a $25 \mathrm{~mm}$ thick midsection slice. This slice was then cut vertically into two $17 \mathrm{~mm}$ exterior sections and one $34 \mathrm{~mm}$ interior section. Starting at the bottom, the vertical sections were cut horizontally into six pieces $25 \mathrm{~mm}$ each. These pieces were crushed and pulverized to minus No. 50 mesh. The $\mathrm{SO}_{3}$ contents and $\mathrm{Na}_{2} \mathrm{O}$ contents were determined. The distributions of $\mathrm{SO}_{3}$ contents and $\mathrm{Na}_{2} \mathrm{O}$ contents are schematically shown in Fig. 9.

The salt distribution in the concrete cylinder provides a powerful evidence supporting that salt weathering is not the major mechanism causing concrete damage.

Based on the above review on the basic principles of salt weathering, supersaturation is the key factor for the salt crystallization. The salt crystals will deposit from the solution during the process of salt crystallization, however, the salt concentration of pore solution must be maintained high for the formation of supersaturation during the whole process. I.e. the salt contents should be highest where salt crystallization distress occurs in the concrete. This is 
the reason why the position where $\mathrm{Na}_{2} \mathrm{O}$ content is highest corresponds with most severe deterioration of concrete exposed to $\mathrm{Na}_{2} \mathrm{CO}_{3}$ and $\mathrm{NaCl}$ solutions. However the situation is opposite in the case of $\mathrm{Na}_{2} \mathrm{SO}_{4}$, the position, where $\mathrm{SO}_{3}$ content is highest, locates on the top portion of cylinder that shows little or no deterioration ( as shown the black line ).

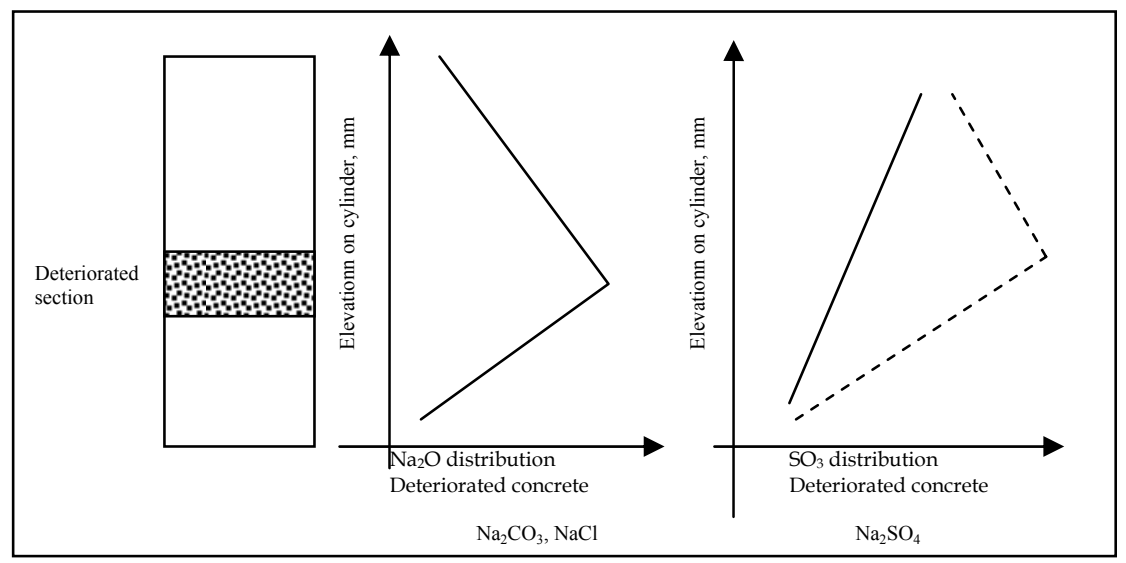

Fig. 9. Schematic of salt distribution in the concrete cylinders

In summary, based on the above analysis of indoor tests, two conclusions can be deduced:

1. Concrete partially exposed to $\mathrm{Na}_{2} \mathrm{SO}_{4}$ is susceptive to being more severely deteriorated under high $\mathrm{RH}$ environment than low RH environment. This appearance is in conflict with the basic principles of salt weathering.

2. The most severe deterioration does not occur in the portion of concrete containing the highest sulfates content. This is also in conflict with the basic principles of salt weathering.

\subsection{Our tests ${ }^{[53,54]}$}

The starting point of our tests is to find a trace of salt crystals in the concrete as a direct evidence by means of XRD, SEM and EDS [53,54]. Sulfate crystals can be easily identified in stone [23, 55]. However, in case of concrete elements, it is hard to identify them. Concrete technologists always attribute this to the coring and sawing operations when preparing samples for experimental analysis, as lapping water can readily dissolve salts from original and treated surfaces $[2,3,4]$. However this is not the main cause for the problem. Samples also can be taken in a dry manner to avoid the influence of water. Furthermore, In our study, the tests were designed to avoid the influence of water within the detection process of sulfate crystals.

Cement paste and cement - fly ash paste specimens and normal concrete specimens were partially exposed to $\mathrm{Na}_{2} \mathrm{SO}_{4}$ and $\mathrm{MgSO}_{4}$ solution under constant and fluctuating storage conditions respectively. After a period of exposure, the specimens were moved out from the solution and did not touch solution or water any more. The surface of the specimens was cleared by a thin blade and a soft brush. The samples for XRD and SEM were dried in a vacuum container with silica gel. 


\subsubsection{Cement paste partially exposed to $\mathrm{Na}_{2} \mathrm{SO}_{4}$ and $\mathrm{MgSO}_{4}$ solution under a constant storage condition}

The test of cement paste specimens $(20 \times 20 \times 150 \mathrm{~mm})$ partially exposed to $\mathrm{Na}_{2} \mathrm{SO}_{4}$ and $\mathrm{MgSO}_{4}$ solution under a constant storage condition $\left(20^{\circ} \mathrm{C}\right.$ and $\left.60 \% \mathrm{RH}\right)$ is based on the study performed by Ruiz-Agudo [42] in which limestone specimens were partially submerged in a $19.4 \mathrm{~g} / 100 \mathrm{ml}$ sodium sulfate solution and a $33.5 \mathrm{~g} / 100 \mathrm{ml}$ magnesium sulfate solution respectively and located in a controlled environment $\left(20^{\circ} \mathrm{C} \pm 2{ }^{\circ} \mathrm{C}\right.$, and $\left.45 \% \pm 5 \% \mathrm{RH}\right)$. Results showed that the limestone specimens were severely damaged in both cases. While salt weathering by sodium sulfate consisted of a detachment of successive stone layers, magnesium sulfate induced the formation and propagation of cracks within the bulk stone. Thenardite $\left(\mathrm{Na}_{2} \mathrm{SO}_{4}\right)$ and epsomite $\left(\mathrm{MgSO}_{4} \cdot 7 \mathrm{H}_{2} \mathrm{O}\right)$ crystals were identified by ESEM in the pores of limestone.

Before immersion minor shrinkage cracks were observed in the cement paste specimens. These cracks were focused upon in detail because narrow micro-fissures appear to be important in the decay process due to the effectiveness of crystallization pressure generated by salt growth [37]. So, if crystallization is the mechanism of decay of cement paste, salt crystallization should first occur in the shrinkage cracks and sodium sulfate or magnesium sulfate crystals should be identified in these cracks.

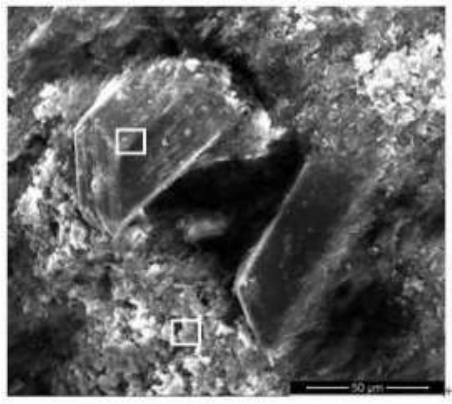

(a)

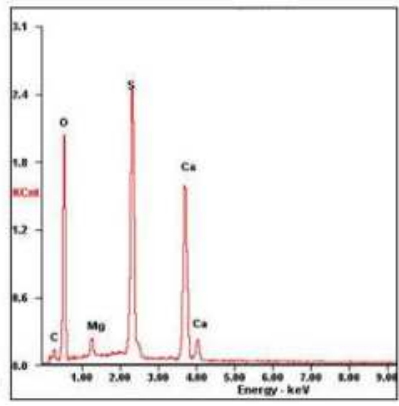

(b)

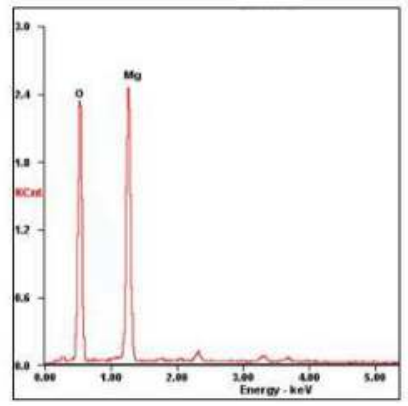

(c)

Fig. 10. ESEM and EDS analysis of white substance on the surface of shrinkage crack [54]

(a) ESEM image of white substance (b) EDS analysis of prismatic crystal

(c) EDS analysis of flocculent crystals

However, based on the micro-analysis results the sulfate crystals were not detected in the atmospheric part of the paste partially exposed to $\mathrm{Na}_{2} \mathrm{SO}_{4}$ solution. On the contrary large amounts of ettringite crystals, the main chemical sulfate attack product, were identified as the reason for paste spalling. Another important observation is that a layer of white substance was formed on the surface of shrinkage cracks in the atmospheric part of the paste partially exposed to $\mathrm{MgSO}_{4}$ solution. Two distinct crystals can be distinguished: prismatic crystals surrounded by flocculent crystals. According to the EDS analysis, the prismatic crystal is gypsum and the flocculent crystal is brucite (shown in Fig.10). The products of this white substance in the shrinkage cracks are the same as the products in the interfacial zone of concrete fully immersed in magnesium sulfate solution [56]. 


\subsubsection{Cement - fly ash paste partially exposed to $\mathrm{Na}_{2} \mathrm{SO}_{4}$ solution under a constant storage condition}

Cement - fly ash paste specimens $(20 \times 20 \times 150 \mathrm{~mm})$ were partially exposed to $\mathrm{Na}_{2} \mathrm{SO}_{4}$ solution. After 5 months exposure under the constant storage condition $\left(20^{\circ} \mathrm{C}\right.$ and $\left.60 \% \mathrm{RH}\right)$, some cracks were found near the upper edge above solution level of the cement-fly ash paste specimen. Along the crack, small pieces were carefully broken off using a thin blade. The ESEM image of a small piece is shown in Fig. 11.

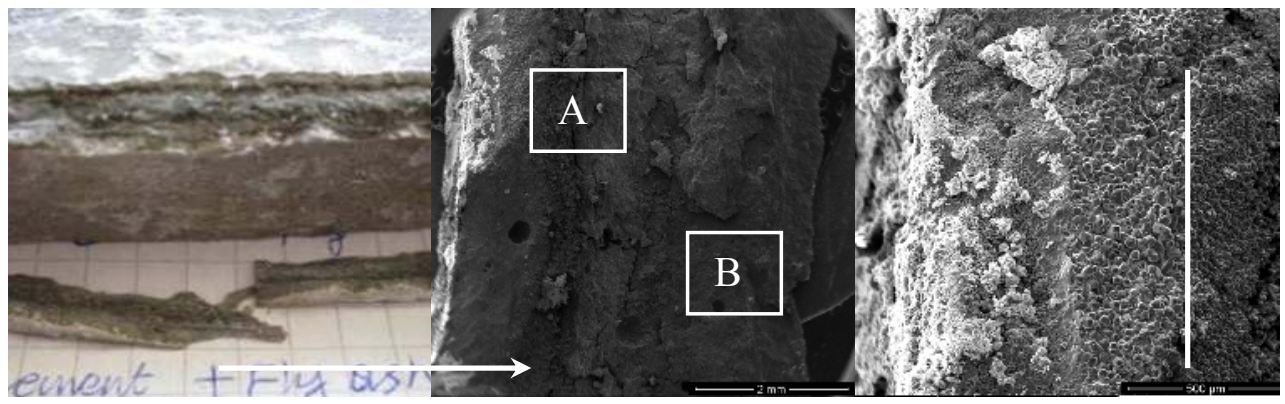

Fig. 11. Cracks in cement - fly ash paste [54]

The middle image is the zoomed surface of a small piece with magnification of 25 times. The left side is the outer surface of paste in contact with air, and zone A is the surface of a crack. Zone $\mathrm{B}$ is a small point in the bulk of paste.

Two distinct parts can be observed at the right and left hand side of the white line in Zone A. At the right side a large amount of dense granular crystals cover the surface (Fig. 12), while at the left side porous crystals can be found accompanied with white substance (Fig. 13). It can be found that the crystals at left and right sides are both calcite. However, some calcite crystals at left side are peeled off and crystal caves are left. Some crystals are honeycombed with small pores. According to the EDS analysis, Na and S are also present. Obviously, the crystallization of sodium sulfate results in damage of the calcite crystals. At the right side, the calcite crystals show no damage.
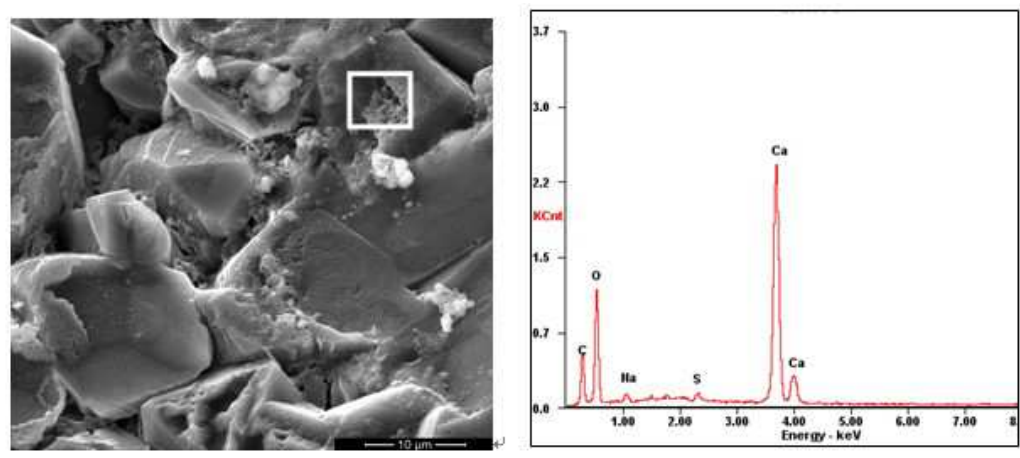

Fig. 12. ESEM image and EDS analysis of $\mathrm{f}$ the granular crystal at left side [54] 

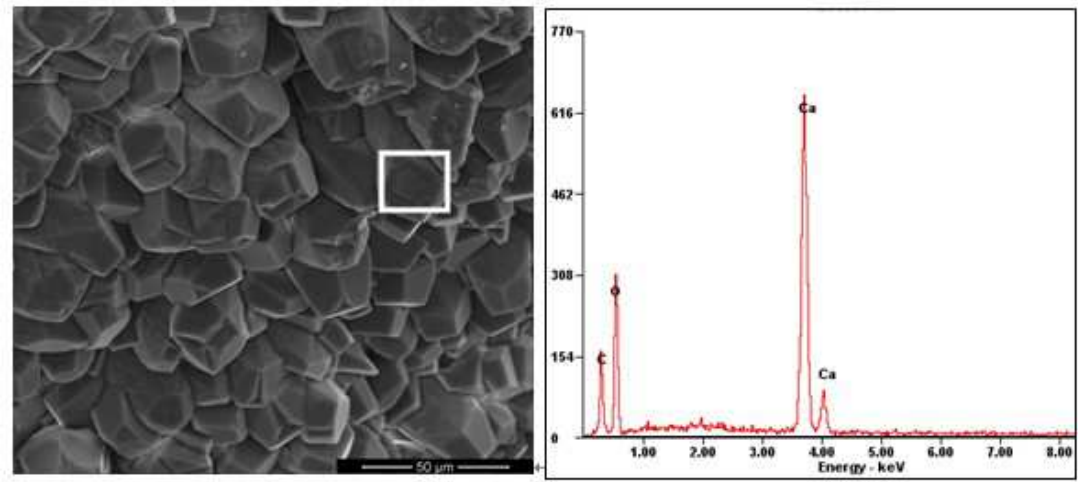

Fig. 13. ESEM image and EDS analysis off the granular crystal at right side [54]

According to the above observation, two conclusions can be drawn:

1. If salt crystallization is causing crack formation, the salt crystals should be identified at the right side in Fig. 11 to form sub-efflorescence instead of in the area in contact with air.

2. Salt crystallization can occur in the calcite crystals.

As we know, the crack formation is attributed to some expansive products present in the paste. When a small piece was broken off along the crack, the inner zone B on the surface of piece was a weak part in the paste and the source of crack initiation. The analysis of the products in this zone can disclose the real reason for the crack formation. Fig. 14 shows the ESEM image of the surface of Zone B.

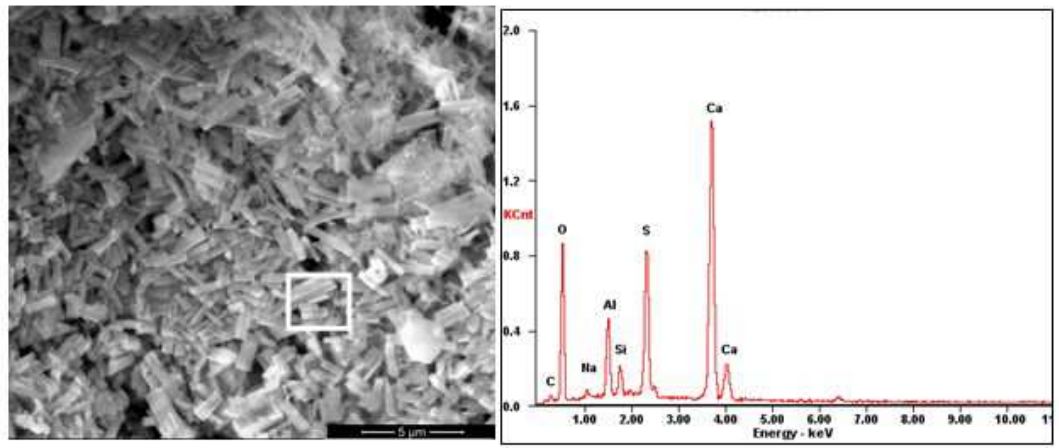

Fig. 14. ESEM and EDS analysis of white square [54]

In Fig. 14, a large amount of short needle crystals are found in this zone. According to the EDS analysis, there are $\mathrm{Ca}, \mathrm{Al}, \mathrm{Si}, \mathrm{S}, \mathrm{Na}$, and $\mathrm{O}$ elements. Combining the XRD analysis, thenardite was not identified and the crystals were ettringite. 


\subsubsection{Cement - fly ash paste partially exposed to $\mathrm{Na}_{2} \mathrm{SO}_{4}$ solution under a fluctuating condition}

Specimens $(10 \times 40 \times 150 \mathrm{~mm})$ were placed in a fluctuating condition $\left(40 \pm 2^{\circ} \mathrm{C}\right.$ and $35 \pm 5 \% \mathrm{RH}$ for 24 hours, $10 \pm 1^{\circ} \mathrm{C}$ and $85 \pm 5 \% \mathrm{RH}$ for 24 hours). After 3 cycles they were broken into several small pieces along some cracks. We checked the products on the surface of a crack. Fig. 15 shows the SEM image and EDS analysis.
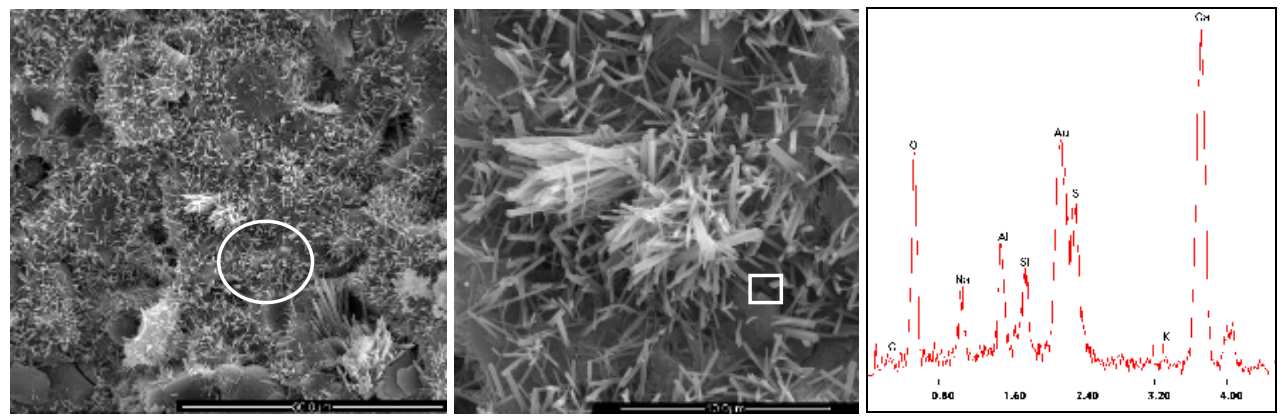

Fig. 15. SEM image and EDS analysis of the surface of a crack [54]

It can be found that a large amount of needle-like crystals grow on the surface like a hedgehog. Some pores are filled with a cluster of the needle-like crystals. Based on the EDS analysis and combining the XRD analysis, the needles are ettringite.

\subsubsection{Normal concrete partially exposed to $\mathrm{Na}_{2} \mathrm{SO}_{4}$ and $\mathrm{MgSO}_{4}$ solution under a constant storage condition}

As we know, in concrete the weak interfacial transition zone (ITZ) plays a particularly important and even determining role in the main characteristic of concrete. A number of full immersion tests already showed that concrete deterioration occurred first in the ITZ by sulfate attack [56-60]. In this test, the concrete was made with just cement and aggregate to emphasize the role of ITZ in concrete deterioration. The concrete specimens $(10 \times 40 \times 150$ mm) were partially exposed to $\mathrm{Na}_{2} \mathrm{SO}_{4}$ and $\mathrm{MgSO}_{4}$ for 8 months. The results showed that: (1) the harmful effect of $\mathrm{MgSO}_{4}$ is much weaker than $\mathrm{Na}_{2} \mathrm{SO}_{4}$. This appearance also cannot be explained by the mechanism of salt weathering. This will be discussed in detail in section 4 ; (2) in the case of $\mathrm{Na}_{2} \mathrm{SO}_{4}$, damage also initiated in the ITZ. A large amount of gypsum crystals were formed on the surface of cement paste of ITZ in the upper part of concrete above solution (shown in Fig. 16).

Besides, the effect of carbonation on the salt weathering on concrete was studied. Before exposure a group of concrete cylinders were placed in an accelerated carbonation chamber with $10 \% \mathrm{CO}_{2}$ concentration at $20 \pm 2{ }^{\circ} \mathrm{C}$ and $60 \% \pm 5 \% \mathrm{RH}$ for 14 days. Then, these cylinders were partially exposed to $\mathrm{Na}_{2} \mathrm{SO}_{4}$ solution. After 8 months exposure, the carbonated cylinders were deteriorated more severely than normal concrete (shown in Fig. 17).

During the process of cleaning the surface of cylinders, a lot of small mortar pieces could be easily brushed off. According to the XRD analysis (Fig.18) $\mathrm{Na}_{2} \mathrm{SO}_{4}$ crystals and $\mathrm{CaCO}_{3}$ crystals were present in the mortar. This appearance also means that salt crystallization can occur in the $\mathrm{CaCO}_{3}$ crystals. 

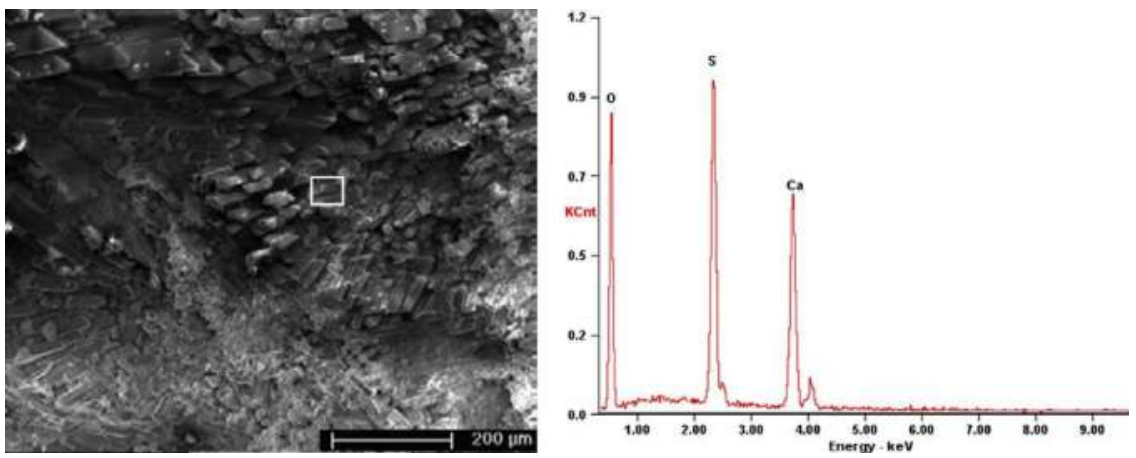

Fig. 16. ESEM image and EDS analysis of surface of cement paste [53]

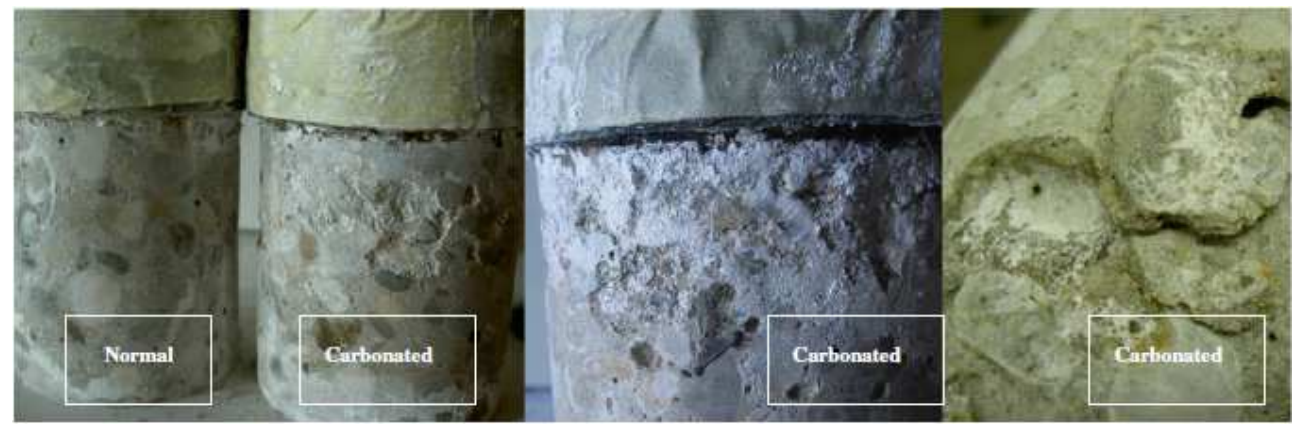

Fig. 17. Visual observation of normal and carbonated concrete specimens exposed to sodium sulfate solution [53]

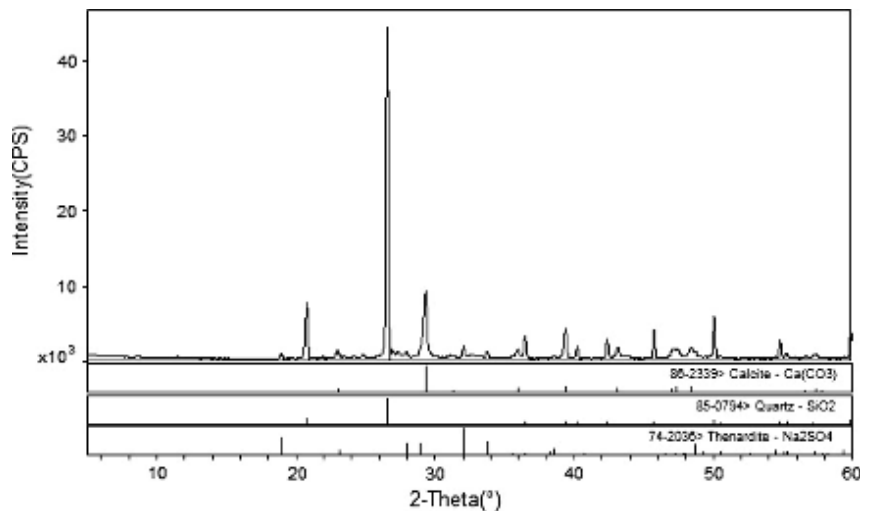

Fig. 18. XRD pattern of mortar [53]

In summary, according to the above test results, two main conclusions can be deduced:

1. Sulfate crystals cannot be identified in the cement paste or concrete partially exposed to $\mathrm{Na}_{2} \mathrm{SO}_{4}$ and $\mathrm{MgSO}_{4}$ solutions. The chemical reaction products, ettringite, gypsum and brucite, were the determining factors for material damage. 
2. Salt crystallization can occur in the calcite crystals, the carbonated products of concrete.

\subsection{Summary}

The "salt weathering" on concrete was just received a lot of attention in the recent years. Based on the above analysis of a limited number of research reports, the experimental results already showed convincing appearances that were completely opposite to the basic principles of salt weathering distress on porous materials. On the contrary, the experimental results of long term field tests and indoor tests rather tended to indicate that chemical sulfate attack is the mechanism for the concrete damage.

\section{Further research}

According to the limited literature review, the conclusion can be made that the so-called "salt weathering" on concrete in effect is rather chemical sulfate attack. In order to systematically disclose the principles of this appearance, some issues should be further studied.

\subsection{Study of the reason why salt crystallization cannot occur in concrete}

The reason why salt cannot occur in concrete may be explained as follows:

Sulfates likely do not crystallize in a cement paste because in the highly alkaline pore solution other less soluble salts, e.g. ettringite, or gypsum, are preferably precipitated according to chemical equilibria theory. Salt crystallization in porous materials is difficult because salt crystallization occurrence has to reach and even exceed a thresholdsupersaturation. However, the chemical reactions in pore solution can occur regardless of the sulfate concentration and decrease the possibility of physical attack due to consuming sulfates and decreasing the sulfate concentration of pore solution, moreover, high concentration solution will increase the rate of chemical reaction. This will make it is very difficult that the pore solution reaches supersaturation.

In Fig. 9, the $\mathrm{SO}_{3}$ distribution showed some powerful evidence that the sulfates were consumed, resulting in the severest concrete damage. I.e. if there was no chemical reaction and if it were salt weathering causing concrete damage, the ion distribution curves of $\mathrm{Na}_{2} \mathrm{SO}_{4}$ should show similar features to $\mathrm{Na}_{2} \mathrm{O}$ distribution of $\mathrm{Na}_{2} \mathrm{CO}_{3}$ and $\mathrm{NaCl}$. Certainly, this explanation is not convincing enough to disclose the mechanism. Further studies may be performed through thermodynamic calculation to check the negative effect of chemical reaction on the supersaturation formation.

\subsection{Study of the concentration of solution on the formation of pore solution zone in concrete}

In the previous tests, an opposite appearance to salt weathering was that the concrete was susceptive to be damaged under a higher relative humidity condition. Combining the role of relative humidity in wick action and chemical sulfate attack, it can be explained that a wider sulfate pore solution can be formed in the upper part of concrete in contact with moist air and chemical sulfate attack occurring in the pore solution zone resulted in concrete damage. 
In our previous study [61], the pore solution expression test method was used to squeeze the pore solution in the cement paste. Cement paste samples were partially exposed to $10 \%$ $\mathrm{Na}_{2} \mathrm{SO}_{4}$ solution under the constant storage condition $\left(20^{\circ} \mathrm{C}\right.$ and $\left.60 \% \mathrm{RH}\right)$. The sulfate concentrations of pore solution in the lower part under solution (labeled L), film zone (labeled M) and efflorescence zone (labeled U) (shown in Fig. 4) were measured respectively. Fig. 19 gives the results.

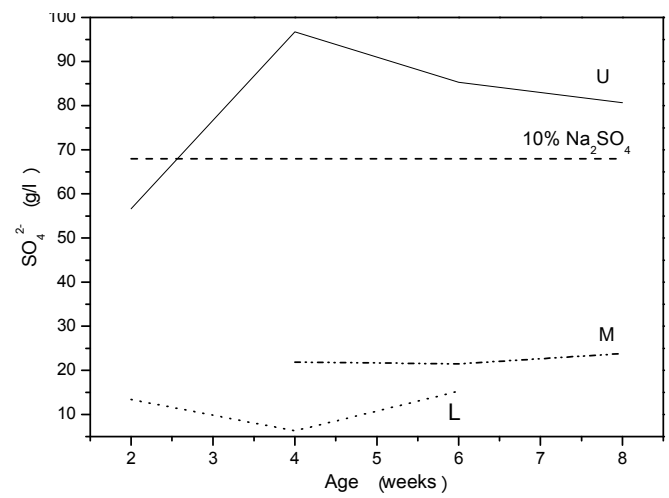

Fig. 19. $\mathrm{SO}_{4}^{2-}$ concentration of different parts of the cement paste partially exposed to the $10 \% \mathrm{Na}_{2} \mathrm{SO}_{4}$ solution [61]

The results confirm that a pore solution zone can be formed in the efflorescence zone in the concrete, and the sulfate concentration was much higher than the lower part under solution and even the exposure solution ( $10 \%$ by mass). The strong chemical reactions occurring in this high concentration pore solution cause severe concrete decay. This also confirms the wick action theory.

Certainly, the ambient temperature and relative humidity of environment are always fluctuating. The boundary, the sulfate concentration and the formation time of pore solution zone were controlled by the evaporation rate due to the interactive effect of temperature and relative humidity. To study the pore solution zone formation needs further study.

\subsection{Study of chemical sulfate attack mechanism}

As we know, the main hydrated phases of cement paste are calcium silicate hydrate (C-S-H), calcium hydroxide $(\mathrm{CH})$, calcium aluminate hydrate $(\mathrm{C}-\mathrm{A}-\mathrm{H})$ ettringite $(\mathrm{AFt})$ and monosulfoaliuminate (AFm). However, these three hydrated phases are not stable in the external environment containing sulfates. The following reactions can occur [62]:

$$
\begin{gathered}
\mathrm{Ca}(\mathrm{OH})_{2}+\mathrm{C}-\mathrm{S}-\mathrm{H}+\mathrm{SO}_{4}^{2-}+\mathrm{H}_{2} \mathrm{O} \rightarrow \mathrm{CaSO}_{4} \cdot 2 \mathrm{H}_{2} \mathrm{O} \\
\mathrm{Ca}(\mathrm{OH})_{2}+\mathrm{C}-\mathrm{S}-\mathrm{H}+\mathrm{MgSO}_{4}+\mathrm{H}_{2} \mathrm{O} \rightarrow \mathrm{CaSO}_{4} \cdot 2 \mathrm{H}_{2} \mathrm{O}+\mathrm{Mg}(\mathrm{OH})_{2}+\mathrm{SiO}_{2} \times \mathrm{H}_{2} \mathrm{O} \\
3 \mathrm{CaO} \cdot \mathrm{Al}_{2} \mathrm{O}_{3} \cdot \mathrm{Ca}(\mathrm{OH})_{2} \cdot(12-18) \mathrm{H}_{2} \mathrm{O}+\mathrm{SO}_{4}^{2-} \cdot 2 \mathrm{H}_{2} \mathrm{O}+\mathrm{H}_{2} \mathrm{O} \rightarrow 3 \mathrm{CaO} \cdot \mathrm{Al}_{2} \mathrm{O}_{3} \cdot 3 \mathrm{CaSO}_{4} \cdot 32 \mathrm{H}_{2} \mathrm{O} \\
\mathrm{Ca}(\mathrm{OH})_{2}+\mathrm{C}-\mathrm{S}-\mathrm{H}+\mathrm{SO}_{4}^{2-}+\mathrm{CO}_{3}^{2-}+\mathrm{H}_{2} \mathrm{O} \rightarrow \mathrm{CaSiO}_{3} \cdot \mathrm{CaCO}_{3} \cdot \mathrm{CaSO}_{4} \cdot \mathrm{H}_{2} \mathrm{O}
\end{gathered}
$$


The main reaction products are gypsum, ettringite, thaumasite, brucite and silica gel. Gypsum and ettringite are the common products of sulfate attack. Brucite and silica gel are found in case of magnesium sulfate. Thaumasite is formed when $\mathrm{CO}_{3}{ }^{2-}$ is presented.

However, the product formation depends on the exposure conditions, such as sulfate content and $\mathrm{pH}$ value of sulfate environment, temperature and relative humidity.

Concerning gypsum, Bellmann et al have discussed the influence of sulfate concentration and $\mathrm{pH}$ value of solution on the gypsum formation in detail [52]. They indicate that portlandite will react to gypsum at a minimal sulfate concentration of approximately 1400 $\mathrm{mg} / \mathrm{l}(\mathrm{pH}=12.45)$. With rising $\mathrm{pH}$, higher concentrations of sulfate ions are needed for the reaction to proceed. Between $\mathrm{pH}$ values of 12.45 and 12.7, the sulfate concentration slowly increases, whereas it rises dramatically from that level on. In solutions in which sodium ions are the counterpart of the hydroxide ions, the precipitation of gypsum can take place until $\mathrm{pH}$ values of approximately 12.9. Beyond that mark, a further increase of the sulfate concentration is unable to lead to the formation of gypsum [52].

Concerning ettringite, ettringite is not stable in an environment with $\mathrm{pH}$ value below 11.512.0. At this low $\mathrm{pH}$ range, ettringite decomposes and forms gypsum [63, 64].

Concerning thaumasite, a number of experimental studies show that a high $\mathrm{pH}$ value (above 10.5) is in favor of the thaumasite formation [65-67]. If the $\mathrm{pH}$ value drops below 10.5 and even further towards 7, thaumasite is unstable, calcite and another calcium-bearing phase will be generated in the field cases [68, 69]. Thaumasite formation needs a relatively cold condition (below $\left.15^{\circ} \mathrm{C}\right)^{[70]}$.

In summary, the sulfate concentration, $\mathrm{pH}$ value and temperature control the reaction products.

Normally, in the full immersion test, $5 \%$ sulfate solutions stored at $23.0 \pm 2.0^{\circ} \mathrm{C}$ are used in laboratories [71]. Compared to ground water in the field, a 5\% sulfate solution used in the tests is much more concentrated [72]. Thus, the concrete immersed in the $5 \%$ sulfate solution can be regarded as an accelerated test. However, a high sulfate contents pore solution (higher than 5\% and 10\%) can be formed in the concrete in contact with air (Fig. 19) [61]. Due to concrete carbonation the $\mathrm{pH}$ value of pore solution in the concrete will decrease. The ambient temperature during the process of salt weathering in the field is always fluctuating. The exposure conditions of "salt weathering" on concrete are different from the full immersion tests. According to the XRD analysis, the results of long term field tests and indoor tests indicated that gypsum likely was the main reaction products and responsible for the concrete damage $[2,45,46,53]$. Certainly, the mechanism of chemical sulfate attack should be further and systematically studied.

\subsection{Study of the role of mineral additions in "Salt weathering" on concrete}

An important result of long term field tests is the negative role of mineral additions in the concrete sulfate resistance. Normally, the indoor tests ${ }^{[74-80]}$ always showed that the mineral additions can improve the sulfate resistance of cementitious materials based on the full immersion in $5 \%$ sulfate solutions stored at $23.0 \pm 2.0^{\circ} \mathrm{C}$. However, the long term field tests showed that the mineral additions accelerated the concrete decay. 
As pointed out by Mehta [73], when concrete is fully immersed in the sulfate solution, for the prevention of sulfate attack "control of permeability is more important than control of the chemistry of cement". The pore size refinement due to mineral additions will prevent the sulfates to penetrate into concrete and lighten the negative effect of sulfate attack on concrete. Therefore, a number of previous researches all supported the idea that the mineral additions, such as fly ash, slag powder, silica fume and metakaolin, play a positive role in making sulfate-resisting concrete [74-80], not depending on the exposure conditions (sodium sulfate, magnesium sulfate, or ammonium sulfate).

However, in the case of partial immersion the pore size refinement due to mineral addtions will contribute to an increase in the capillary sorption height following Eq. 5. The pore solution expression tests showed that this process can draw more sulfates into fly ash concrete than into normal concrete, resulting in a pore solution with a higher sulfate concentration as shown in Fig. 20 [61].

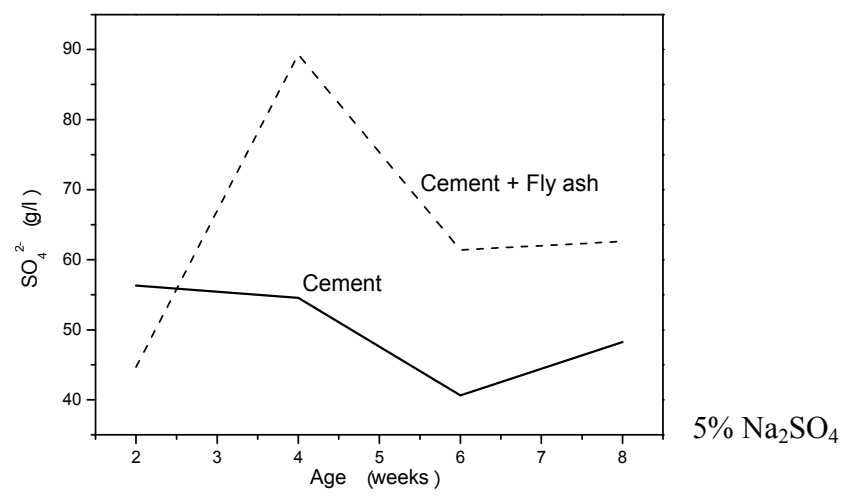

Fig. 20. $\mathrm{SO}_{4}{ }^{2-}$ concentration of the pore solution in efflorescence and film zone of cement paste and cement-FA paste exposed to $5 \% \mathrm{Na}_{2} \mathrm{SO}_{4}$ solution [61]

Another reason for mineral additions to lighten the negative effect of sulfate attack on concrete is the dilution effect induced by the partial cement replacement since it entails a reduction in the $\mathrm{C}_{3} \mathrm{~A}$ content [81]. Thus, based on laboratory tests mineral additions have always been regarded as an effective constituent to increase concrete's sulfate resistance in the field [82]. However, people maybe just remember the good things and ignore the bad ones. In the 1960s and 1970s extensive studies at the U.S. Bureau of Reclamation had reminded that $[83,84]$ concretes containing 30 percent low-calcium fly ashes showed greatly improved sulfate resistance to a standard sodium sulfate solution. However, the use of highcalcium fly ashes generally reduced the sulfate resistance. The high-calcium fly ashes containing highly reactive alumina in the form of $\mathrm{C}_{3} \mathrm{~A}$ or $\mathrm{C}_{4} \mathrm{~A}_{3} \hat{\mathrm{S}}$ are therefore less suitable than low-calcium fly ashes for improving the sulfate resistance of concrete. Taylor also pointed out that if slag has low alumina content, it improves the sulfate resistance, but with a high content of alumina, the reverse is the case ${ }^{[85,86]}$. M. Nehdi ${ }^{[47]}$ also pointed out that it should not be overlooked that fly ash contains a large amount of reactive aluminum and that binders with an increased $\mathrm{Al}_{2} \mathrm{O}_{3}$ content can be more susceptive to the formation of ettringite. P. Nobst and J. Stark [87] carried out a very interesting test. Hardened cement 
pastes modified by different mineral additions were ground to a fineness of $<200 \mu \mathrm{m}$ and were mixed with stoichiometric parts of high quality gypsum powder $\left(\mathrm{CaSO}_{4} \cdot 2 \mathrm{H}_{2} \mathrm{O}\right)$ and chemically produced calcite $\left(\mathrm{CaCO}_{3}\right)$ as well as with an excess of $20 \%$ of distilled water to investigate the thaumasite formation without the physical obstacle. The products identification showed unexpected results: (1) concerning cement-FA paste, the amount of ettringite increased with an increasing $\mathrm{Al}_{2} \mathrm{O}_{3}$ content at $20^{\circ} \mathrm{C}$ while at $6{ }^{\circ} \mathrm{C}$ fly ash promoted a little more thaumasite formation; (2) slag cements which are generally classified as high sulfate resisting cements showed the most intensive thaumasite formation; (3) the use of micro-silica strongly accelerated the thaumasite formation. These findings indicate that mineral additions have a potentially negative effect in the concrete's resistance to sulfate attack depending on the exposure conditions. In the paper [87], the negative effect emerged due to no physical obstacle.

In the fly ash the aluminum phase existing as solid glass spheres is stable, but can be activated in a thermal, mechanical or chemical way [88]. It should be noted that $\mathrm{Na}_{2} \mathrm{SO}_{4}$ is an effective activator which is often used to activate the pozzolanic fly ash reaction in cementfly ash pastes [89, 90]. What is worse, the ambient temperature may rise and also play a positive role in activating the aluminum phase, promoting the ettringite formation. According to the thermal analysis results [61], the cement and cement - fly ash (25\%) pastes were immersed in the $5 \% \mathrm{Na}_{2} \mathrm{SO}_{4}$ solution at $30{ }^{\circ} \mathrm{C}$ for 6 months. The amount of ettringite in the cement and cement-FA pastes amounted to $0.173 \mathrm{mg} / \mathrm{mg}$ and $0.217 \mathrm{mg} / \mathrm{mg}$ respectively. On the other hand, more gypsum was also detected in the cement - fly ash paste than cement paste. Fig. 21 is the thermal analysis of pastes exposed to $15 \% \mathrm{Na}_{2} \mathrm{SO}_{4}$ solution at $30^{\circ} \mathrm{C}$ for 6 months. More ettringite and gypsum were generated in the cement fly ash paste than in cement paste. Moreover, according to the wick action, $15 \% \mathrm{Na}_{2} \mathrm{SO}_{4}$ can be formed in the upper portion of concrete in contact with air during the process of "salt weathering" on field concrete.

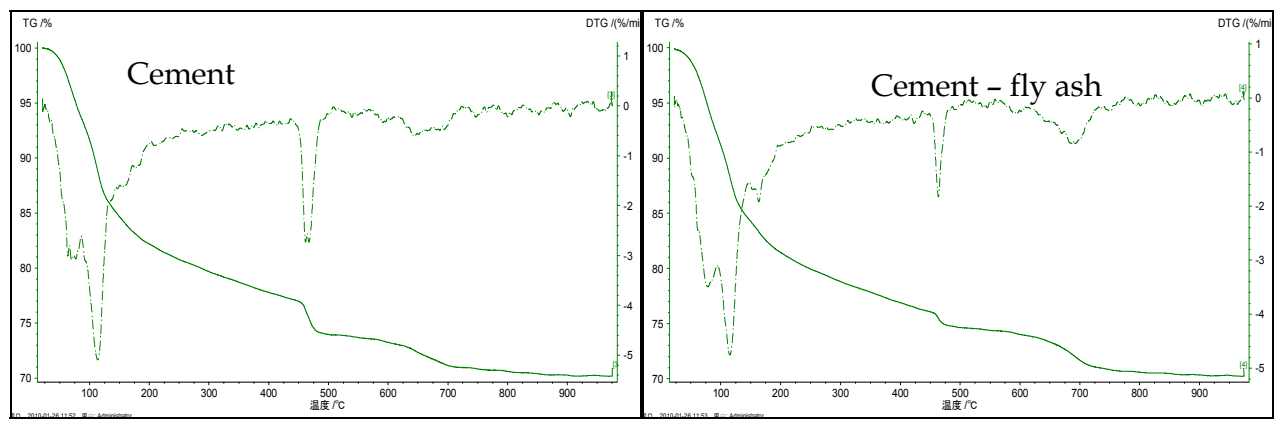

Fig. 21. Thermal analysis of pastes partially immersed in the $15 \% \mathrm{Na}_{2} \mathrm{SO}_{4}$ solution at $30 \circ \mathrm{C}$ for 6 months [61]

In the paper [87], the negative effect of mineral additions on concrete sulfate resistance opposite to the normal results was attributed to no physical obstacle. In the process of "salt weathering" on concrete, a similar no physical obstacle appearance also can be defined. As abovementioned, solution goes into concrete by capillary suction. For porous materials, the capillary suction is a kind of active process, i.e. the solution is invited into the concrete. This can also be regarded as a no physical obstacle process. The sulfates can homogeneously 
distribute in the cement paste similar to the alkali activated cement in which $\mathrm{Na}_{2} \mathrm{SO}_{4}$ and powders are mixed before adding water, resulting in $\mathrm{Na}_{2} \mathrm{SO}_{4}$ homogeneously distributing in the cement paste.

In summary, concerning the role of mineral additions in the sulfate attack on partially exposed concrete, the exposure conditions and the solution transport mechanism are different from the full immersion cases. It needs further research.

\subsection{Study of the effect of different kinds of sulfates in "salt weathering" on concrete}

As abovementioned, Ruiz-Agudo [42] studied salt weathering distress of limestone specimens submerged in sodium sulfate and magnesium sulfate solutions respectively. The results showed that these two sulfates both severely damaged stone.

In the full immersion attack, because of the simultaneous significant decomposition of the C-S-H gel that accompanies the formation gypsum and ettringite, admittedly, people think the overall corrosive action of magnesium sulfate is greater than that of sodium sulfate [81,91]

However, during the process of "salt weathering" on concrete, the test results showed the opposite appearance. Nehdi and Hayek [47] observed the appearances of the cement mortar partially exposed to $10 \%$ sodium sulfate and magnesium sulfate solution in a $\mathrm{RH}$ cycling between $32 \pm 3 \%$ and $>95 \%$ condition respectively. The results showed that a large amount of efflorescence covers the surface when mortar is exposed to sodium sulfate solution. On the contrary, the surface of mortar subjected to magnesium sulfate solution is clean. It seems that sodium sulfate performs more corrosive effect on mortar than magnesium sulfate. The tests [53] also showed the same results. The aggregates and cement paste were completely separated in the upper part of concrete after 8 months exposure. However, the samples exposed to magnesium sulfate solution showed little damage. As shown in Fig. 22.
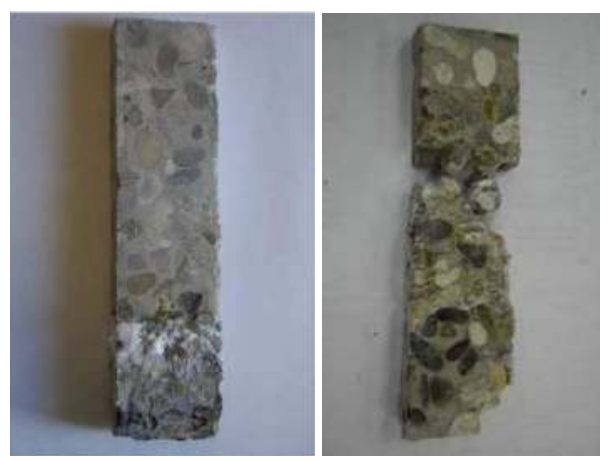

Fig. 22. Visual observation of concrete specimens partially exposed to $\mathrm{Na}_{2} \mathrm{SO}_{4}$ and $\mathrm{MgSO}_{4}$ solutions [53]

This appearance may indicate that the concrete damage cannot be explained by salt weathering. First, $\mathrm{MgSO}_{4}$ showed a harmful effect on stone due to salt weathering. As a porous material concrete should also show a similar scaling manner. Secondly, Fig. 23 shows the surface tensions of $\mathrm{NaCl}, \mathrm{Na}_{2} \mathrm{SO}_{4}$ and $\mathrm{MgSO}_{4}$ [92]. According to Eq. 5 the equilibrium heights of capillary rise of sodium sulfate and magnesium sulfate should be 
almost the same, showing similar efflorescence zone due to salt weathering. The reason for the opposite appearance of $\mathrm{MgSO}_{4}$ in concrete may be the insoluble brucite due to chemical reaction that blocks the capillary. The role of sulfates in the "salt weathering" on concrete also needs further research.

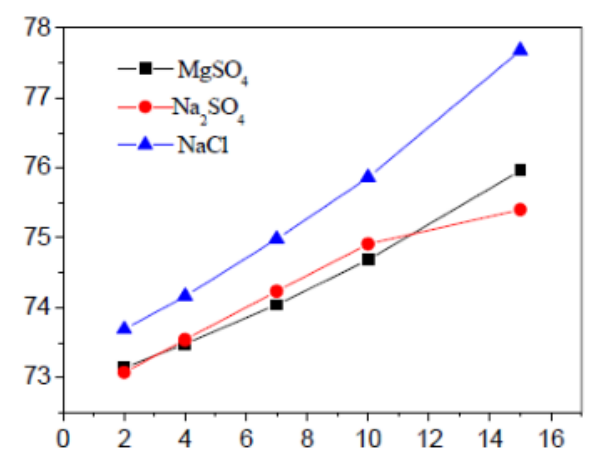

Fig. 23. Surface tensions of $\mathrm{NaCl}, \mathrm{Na}_{2} \mathrm{SO}_{4}$ and $\mathrm{MgSO}_{4}{ }^{[92]}$

\subsection{Study of the role of concrete carbonation in "salt weathering" on concrete}

The negative effect of carbonation on corrosion of reinforcing steel in concrete is well known. As to the sulfate attack on concrete, as a result of carbonation, the total porosity would be reduced and the permeability of concrete could be improved [93-94]. So, Gao [95] pointed out that the carbonation layer could mitigate diffusion of sulfate ions to some extent in the full immersion situation.

However, when the concretes are partially exposed to sulfate solutions, the situation may be different. V.T. Ngala [94] studied the effect of carbonation on the ratio of capillary to total porosity of cement paste. The results showed that the capillary pore fraction greatly was improved after carbonation (shown in Fig. 24). This will promote the capillary suction of concrete, forming a more severe sulfate pore solution in the concrete and resulting more severer concrete damage.
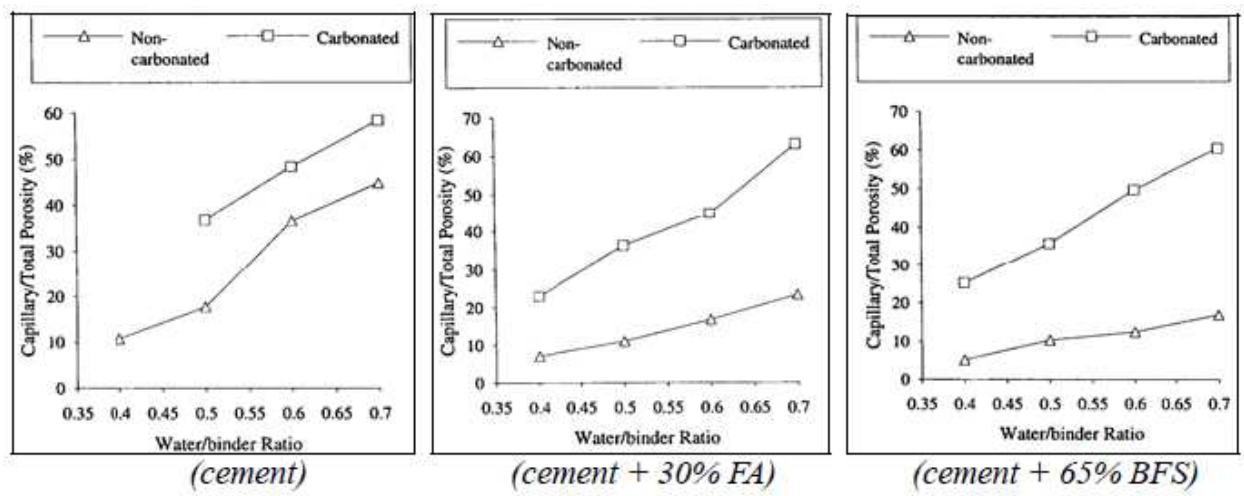

Fig. 24. Ratio of capillary to total porosity of non-carbonated and carbonated paste [94] 
From Fig. 24, compared to cement paste, the ratios of capillary pores fraction of cement + $30 \%$ FA and cement $+65 \%$ BFS were higher than cement paste after carbonation. Some research showed that blended concrete has high carbonation rate [96], high degree of carbonation [97] or large carbonation depth [98] compared to the ordinary cement concrete. The carbonation susceptibility of blended concrete may be another reason for the negative effect of mineral addition on sulfate resistance of partially exposed concrete.

Besides, according to the review of indoor tests of "salt weathering" on concrete, two experimental results were observed showing that sulfate crystallization can be detected in the calcite crystals, the carbonation products of concrete (Fig. 12) and that carbonation could accelerate the concrete damage (Fig. 17). It might be that the efflorescence also occurs after concrete carbonation.

In summary, the effect of carbonation on sulfate resistance of partially exposed concrete is not clear. Further research will contribute to disclose the mechanism of "salt weathering" on concrete.

\section{Conclusions}

"Salt weathering" on concrete by sulfates is a deceptive and misleading phenomenon. In this paper, according to the comparison between the basic principles of salt weathering on porous materials and the abnormal appearances of "salt weathering" on concrete, the conclusion can be drawn that the salt weathering distress is not the major reason causing concrete damage when partially exposed to the sulfate environment. Chemical sulfate attack occurring in a high concentration pore solution is more likely the degradation mechanism for concrete deterioration similar to the full immersion cases of sulfate attack on concrete.

\section{Acknowledgements}

This work was financially supported by the National Science Foundation of P. R. China under contract \#50378092, the scholarship from CSC (China Scholarship Council) and the co-funding from Ghent University of Belgium. The research was performed under a Bilateral Cooperation Agreement between Ghent University of Belgium and Central South University of P.R. China.

\section{References}

[1] D. Benavente, M.A. García Del Cura, A. Bernabéu, S. Ordóñez, Quantification of salt weathering in porous stones using an experimental continuous partial immersion method, Eng. Geol 2001; 59(3-4):313-325.

[2] Harvey Haynes, Robert O'Neill, Michael Neff, and P. Kumar Mehta, Salt weathering distress on concrete exposed to sodium sulfate environment, ACI Mater. J. 2008, 105(1):35-43.

[3] K. J.Folliard, P. Sandberg, Mechanisms of Concrete Deterioration by Sodium Sulfate Crystallization, Durability of Concrete, SP-145, American Concrete Institute, Farmington Hills, MI, 1994: 933-945. 
[4] Haynes, H.; O'Neill, R.; and Mehta, P. K. Concrete Deterioration from Physical Attack by Salts, Concr. Int. 1996, 18 (1):63-68.

[5] W. G. Hime, R. A. Martinek, L. A. Backus, S. L. Marusin, Salt Hydration Distress, Concr. Int. 2001.23(10): 43-50.

[6] Thaulow, Niels, Sahu, Sadananda. Mechanism of concrete deterioration due to salt crystallization, Mater. Charact.2004, 53(2-4):123-127.

[7] YANG Quanbing , YANG Qianrong. Effects of salt-crystallization of sodium sulfate on deterioration of concrete, J. Chin. Chem. Soc 2007, 35(7): 877-880+885 (Chinese).

[8] MA Kunlin, XIE Youjun, LONG Guangcheng, LIU Yunhua. Deterioration characteristics of cement mortar by physical attack of sodium sulfate, J. Chin. Chem. Soc 2007, 35(10):1376-1381.

[9] Harvey Haynes, Robert O'Neill, Michael Neff, and P. Kumar Mehta, Salt Weathering of Concrete by Sodium Carbonate and Sodium Chloride, ACI Mater. J. 2010, 107(3):256-266

[10] Robert J. Flatt, Michael Steiger, George W. Scherer, A commented translation of the paper by C.W. Correns and W. Steinborn on crystallization pressure, Environ. Geol. 2007, 52(2): 221-237.

[11] George W. Scherter, crystallization in pores, Cem. Concr. Res. 1999, 29(8): 1347-1358.

[12] Rosa M. Espinosa Marzal, George W. Scherer, Crystallization of sodium sulfate salts in limestone, Environ. Geol. 2008, 56(3-4): 605-621.;

[13] Robert J. Flatt, Salt damage in porous materials: How high supersaturations are generated, J. Cryst. Growth 2002, 242(3-4): 435-454.

[14] George W. Scherer, Factors affecting crystallization pressure, International RILEM TC 186-ISA workshop and internal sulfate attack and delayed ettringite formation, 2002, Villars, Switzerland.

[15] Michael Steiger, Crystal growth in porous materials - I: The crystallization pressure of large crystals, J. Cryst. Growth 2005, 282(3-4):455-469.

[16] Michael Steiger, Crystal growth in porous materials - II: Influence of crystal size on the crystallization pressure, J. Cryst. Growth 2005, 282(3-4):470-481.

[17] Joerg Ruedrich, Siegfried Siegesmund, Salt and ice crystallization in porous sandstones, Environ. Geol. 2007, 52(2): 343-367.

[18] R.M. Espinosa, L. Franke, G.. Deckelmann, Model for the mechanical stress due to the salt crystallization in porous materials, Constr. Build. Mater. 2008, 22(7):1350-1367.

[19] G. Cultrone, L.G.Russo, C. Calabrò, M. Uroševic, A. Pezzino, Influence of pore system characteristics on limestone vulnerability: A laboratory study, Environ. Geol. 2008, 54(6):1271-1281.

[20] George W. Scherer, Stress from crystallization of salt, Cem. Concr. Res. 2004, 29(9): 1613-1624.

[21] D.Benavente, N. Cueto, J. Martínez-Martínez, M.A. García Del Cura, J.C. Cañaveras, The influence of petrophysical properties on the salt weathering of porous building rocks, Environ. Geol. 2007, 52(2):197-206.

[22] D. Benavente, M.A. Garcia del Cura, R. Fort, S. Ordónez, Durability estimation of porous building stones from pore structure and strength, Environ. Geol. 2004, 74(12): 113-127. 
[23] D. Benavente, J. Martínez-Martínez, N.Cueto, M.A. García-del-Cura, Salt weathering in dual-porosity building dolostones, Environ. Geol. 2007, 94(3-4): 215-226.

[24] V. Lopez-Acevedo, C. Viedma, V. Gonzalez, A. La Iglesia, Salt crystallization in porous construction materials. II. Mass transport and crystallization processes, J. Cryst. Growth 1997, 182(1-2): 103-110.

[25] Miguel Gomez-Heras, Rafael Fort, Patterns of halite $(\mathrm{NaCl})$ crystallisation in building stone conditioned by laboratory heating regimes, Environ. Geol. 2007, 52(2): 239247.

[26] C. Rodriguez-Navarro, E. Doehne, Salt weathering: influence of evaporation rate, supersaturation and crystallization pattern. Earth Surf Processes and Landforms 1999, 24(2-3): 91-209.

[27] C. Rodriguez-Navarro, L. Linares-Fernandez, E. Doehne, E. Sebastian, Effects of ferrocyanide ions on $\mathrm{NaCl}$ crystallization in porous stone, J. Cryst. Growth 2002, 243(3-4): 503-516.

[28] S. Charles, E. Doehne, The evaluation of crystallization modifiers for controlling salt damage to limestone, J. J Cult. Herit. 20023 (3) 205-216.

[29] N.R. Buenfeld, M-T. Shurafa - Daoudi, I. M. Mcloughin, Chloride transport due to wick action in concrete RILEM International Workshop on Chloride Penetration into Concrete 1995:315-324.

[30] J. Francis Yong, Sidney Mindess, Robert J. Gray, Arnon Bentur, The science and technology of civil Engineering materials, Chinese Architecture \& Building Press, 2006.

[31] Y.T. Puyate, C.J. Lawrence, Steady state solutions for chloride distribution due to wick action in concrete, Chem. Eng. Sci. 2000, 55(16): 3329-3334.

[32] Y.T. Puyate, C.J. Lawrence, N.R. Buenfeld, I.M. McLoughlin, Chloride transport models for wick action in concrete at large Peclet number, Phys. Fluids. 1998, 10(3): 566575.

[33] Y.T. Puyate, C.J. Lawrence, Wick action at moderate Peclet number, Phys. Fluids. 1998, 10(8): 2114-2116.

[34] Y.T. Puyate, C.J. Lawrence, Effect of solute parameters on wick action in concrete, Chem. Eng. Sci., 1999, 54(19):4257-4265.

[35] L. Pel, H. Huinink, K. Kopinga, Ion transport and crystallization in inorganic building materials as studied by nuclear magnetic resonance, Appl. Phys. Lett. 2002, 81(15): 2893-2895.

[36] L.Pel, H. Huinink, K. Kopinga, R.P.J.Van Hees, O.C.G. Adan, Efflorescence pathway diagram: Understanding salt weathering, Constr. Build. Mater. 2004, 18(5): 309-313.

[37] C. Cardell, D.Benavente, J. Rodríguez-Gordillo, Weathering of limestone building material by mixed sulfate solutions. Characterization of stone microstructure, reaction products and decay forms, Mater. Charact. 2008, 59 10): p 1371-1385.

[38] Nicholas Tsui, Robert J. Flatt, George W. Scherer. Crystallization damage by sodium sulfate, J. J Cult. Herit. 20034 (2): 109-115.

[39] Genkinger, Selma, Putnis, Andrew, Crystallisation of sodium sulfate: Supersaturation and metastable phases, Environ. Geol. 2007, 52(2): 295-303. 
[40] C. Rodriguez-Navarro, E. Doehne, E. Sebastian, How does sodium sulfate crystallize? Implications for the decay and testing of building materials, Cem. Concr. Res. 2000, 30(10): 1527-1534.

[41] E.M. Winkler, P.C. Singer, Crystallization pressure of salt in stone and concrete, Geol. Soc Am. 1972, 83(11): 3509-351.

[42] E. Ruiz-Agudo, F. Mees, P. Jacobs, C. Rodriguez-Navarro, The role of saline solution properties on porous limestone salt weathering by magnesium and sodium sulfates, Environ. Geol. 2007, 52(2):305-317.

[43] F.R. Mcmillan, T.E. Stantion, I.L. Tyler, W. C. Hansen. Long-Time Study of Cement Performance in Concrete, chapter 5. Concrete exposed of sulfate solis, Portland Cement Association 1949.

[44] D. Stark. Durability of concrete in sulfate-rich soils, Research and Development Bulletin, vol. RD O97, Portland Cement Association, 1989.

[45] D. Stark Performance of Concrete in Sulfate Environments, RD129, Portland Cement Association 2002.

[46] E.F. Irassar, A. Di Maio, O.R. Batic, Sulfate attack on concrete with mineral admixtures, Cem. Concr. Res. 1996, 26(1):113-123.

[47] M. Nehdi, M. Hayek, Behavior of blended cement mortars exposed to sulfate solutions cycling in relative humidity, Cem. Concr. Res. 2005, 35(4): 731-742.

[48] Norah Crammond, The occurrence of thaumasite in modern construction - a review, Cem. Concr. Compo. 2002, 24(3-4): 393-402.

[49] P.W. Brown, April Doerr, Chemical changes in concrete due to the ingress of aggressive species, Cem. Concr. Res. 2000, 30(3): 411-418.

[50] Mingyu, Hu, Fumei, Long, Mingshu, Tang, The thaumasite form of sulfate attack in concrete of Yongan Dam, Cem. Concr. Res. 2006, 36,(10): 2006-2008.

[51] Chiara F. Ferraris, Paul E. Stutzman, Kenneth A. Snyder, Sulfate Resistance of Concrete: A New Approach, Research and Development Information PCA R\&D, Serial No. 2486, 2006.

[52] Bellmann Frank, Möser Bernd, Stark Jochen, Influence of sulfate solution concentration on the formation of gypsum in sulfate resistance test specimen, Cem. Concr. Res. 2006, 36(2): 358-363.

[53] Zanqun Liu, Geert De Schutter, Dehua Deng, Zhiwu Yu, Micro-analysis of the role of interfacial transition zone in "salt weathering" on concrete, Constr. Build. Mater. 2010, 24(11): 2052-2059.

[54] Zanqun Liu, Dehua Deng, Geert De Schutter, Zhiwu Yu, Micro-analysis of "salt weathering" on cement paste, accepted by Cem. Concr. Compo. for publish.

[55] D. Benavente, García del Cura, M.A.,García-Guinea, J, Sánchez-Moral, S, Ordóñez, S, Role of pore structure in salt crystallisation in unsaturated porous stone, J. Cryst. Growth 2004, 260 (3-4): 532-544.

[56] LIU Zanqun, XIAO Jia, HUANG Hai, YUAN Qiang, DENG Dehua. Physicochemical Study on the Interface

[57] Zone of Concrete Exposed to Different Sulfate Solutions, J.Wuhan Univ.Technol. (Materials Science Edition) 2006, 21(z1):167-175. 
[58] Faran J. Introduction: the transition zone - discovery and development. ITZ in concrete RILEM report 11. London: E\&FN Spon; 1996.

[59] Shenyang, Zhongzi Xu, Mingshu Tang, The process of sulfate attack on cement mortars. Adv Cem Based Mater 1996;4(1):1-5.

[60] Bonen David. Micro-structural study of the effect produced by magnesium sulfate on plain and silica fume-bearing Portland cement mortars. Cem. Concr. Res. 1993;23(3):541-55.

[61] Santhanam Manu, Cohen Menashi D, Olek Jan. Mechanism of sulfate attack: afresh look - part I: summary of experimental results. Cem. Concr. Res. 2002;32(6):915-21.

[62] Zanqun Liu, Study of the basic mechanisms of sulfate attack on cementitious materials, 2010, Central and South University China and Ghent University Belgium.

[63] M. Collepardi, A state-of-the-art review on delayed ettringite attack on concrete, Cem. Concr. Compo. 2003 25(4-5): 401-407.

[64] [63]Manu Santhanam, Menashi D, Jan OLek. Sulfate attack research - whither now? Cem. Concr. Res. 2004, 31(8): 1275-1296.

[65] P. Kumar Mehta. sulfate attack on concrete: separating myths from reality, Concr. Int. 2000, 28 (8): 57- 61.

[66] Q. Zhou, J. Hill, E.A. Byars, et al, The role of $\mathrm{pH}$ in thaumasite sulfate attack, Cem. Concr. Res. 2006, 36(1): 160-170.

[67] Jallad, Karim N., Santhanam, Manu, Cohen, Menashi D. Stability and reactivity of thaumasite at different $\mathrm{pH}$ levels, Cem. Concr. Res. 2003, 33(3): 433-437.

[68] N.J. Crammond, The thaumasite form of sulfate attack in the UK, Cem. Concr. Res. 2003, 25(7): 809-818.

[69] P. Hagelia, R.G. Sibbick, N.J. Crammond, C.K. Larsen, Thaumasite and secondary calcite in some Norwegian concretes, Cem. Concr. Compo. 2003, 25(8):1131-1140.

[70] P. Hagelia, R.G.. Sibbick, Thaumasite Sulfate Attack, Popcorn Calcite Deposition and acid attack in concrete stored at the Blindtarmen test site Oslo, from 1952 to 1982, Mater. Charac. 2009, 60(7):686-699.

[71] Deng De-Hua, Xiao Jia, Yuan Qiang, On thaumasite in cementitious materials, Jianzhu Cailiao Xuebao/J. Build. Mater. 2005, 8(4): 400-409 (Chinese).

[72] AETM C 1012 - 04, Standard Test Method for Length Change of Hydraulic-Cement Mortars Exposed to a Sulfate Solution.

[73] H. Haynes, Sulfate Attack on Concrete: Laboratory versus Field Experience, Concr. Int. 2002, 24(7): 64-70.

[74] P.K. Mehta, Sulfate attack on concrete: a critical review, Materials Science of Concrete, vol.III, Amer. Ceramic Society 1993:105- 130.

[75] H.T. Cao, L. Bucea, A. Ray, S. Yozghatlian, The effect of cement composition and $\mathrm{pH}$ of environment on sulfate resistance of Portland cements and blended cements, Cem. Concr. Compo. 1997, 19(2): 161-171.

[76] S. Miletic, M.Ilic, S. Otovic, R.Folic, Y. Ivanov, Phase composition changes due to ammonium-sulphate: Attack on Portland and Portland fly ash cements, Constr. Build. Mater. 1999, 13(3): 117-127.

[77] Rodriguez-Camacho, Redz E., Uribe-Afif, R., Importance of using the natural pozzolans on concrete durability, Cem. Concr. Res. 2003, 32(12): 1851-1858. 
[78] El Sokkary, T.M., Assal, H.H., Kandeel, A.M., Effect of silica fume or granulated slag on sulphate attack of ordinary portland and alumina cement blend, Ceram. Int. 2004, 30(2): 133-138.

[79] P. Chindaprasirt, S. Homwuttiwong, V. Sirivivatnanon, Influence of fly ash fineness on strength, drying shrinkage and sulfate resistance of blended cement mortar, Cem. Concr. Res. 2004, 34(7): 1087-1092.

[80] Hanifi Binici, Orhan Aksogan, Sulfate resistance of plain and blended cement, Cem. Concr. Compo. 2006, 28(1): 39-46.

[81] Nabil M. Al-Akhras, Durability of metakaolin concrete to sulfate attack, Cem. Concr. Res. 2005, 36(9): 1727-1734.

[82] Omar S Al-Amoudi Baghabra, Attack on plain and blended cements exposed to aggressive sulfate environments, Cem. Concr. Compo. 2002, 24(3-4): 305-316.

[83] GB/T 50476-2008, Code for durability design of concrete structures (Chinese standard).

[84] P. Kumar Mehta, Concrete: structure, properties, and materials, Second Edition, Prentice Hall College Div; 2nd Revised edition edition (November 1992);

[85] Monteiro, Paulo J.M., Kurtis, Kimberly E., Time to failure for concrete exposed to severe sulfate attack, Cem. Concr. Res. 2003, 33(7): 987-993,.

[86] R.S. Collop, H. F. W.Taylor, Microstructural and microanalytical studies of sulfate attack III: Sulfate-resisting cement: reactions with sodium and magnesium sulfate solution. Cem. Concr. Res. 1995, 25(7): 1581-1590.

[87] R.S. Collop, H. F. W.Taylor, Microstructural and microanalytical studies of sulfate attack. V. Comparison of different slag blends, Cem. Concr. Res. 1996, 26(7) 10291044.

[88] P. Nobst, J. Stark, Investigations on the influence of cement type on thaumasite formation, Cem. Concr. Compos.2003, 25(8): 899-906.

[89] Wu, Zichao,Naik, Tarun R., Chemically activated blended cement, ACI Mater. J. 2003, 100(5): 434-440.

[90] Shi, Caijun, and Day, Robert L. Pozzolanic reaction in the presence of chemical activators. Part I. Reaction kinetics, Cem Concr Res. 2000, 30(1):51-58.

[91] Shi, Caijun, and Day, Robert L., Pozzolanic reaction in the presence of chemical activators: Part II. Reaction products and mechanism, Cem Concr Res. 2000, 30(4): 607-613.

[92] Omar S. Baghabra Al-Amoudi, Mohammed Maslehuddin, Effect of magnesium sulfate and sodium sulfate on the durability performance of plain and blended cement, ACI Mater. J. 1995, 92(1): 15-24.

[93] Ma Kunlin, Mechanism and Evaluation Method of Salt Crystallization Attack on Concrete, Central South University PhD thesis, 2009;

[94] V.T. Ngala, C.L. Page, Effect of carbonation on pore structure and diffusional properties of hydrated cement paste, Cem Concr Res. 1997, 27(7): 995-1007.

[95] Ha-Won Song, Seung-Jun Kwon, Permeability characteristics of carbonated concrete considering capillary pore structure, Cem Concr Res. 2007, 37 (6): 909-915;

[96] GAO Rundong - ZHAO Shunbo , LI Qingbin, Deterioration Mechanisms of Sulfate Attack on Concrete under the Action of Compound Factors, Jianzhu Cailiao Xuebao/J. Build. Mater. 2009, 12(1): 41-46 (Chinese). 
[97] P. Sulapha, S.F. Wong, T.H. Wee, S. Swaddiwudhipong, Carbonation of concrete containing mineral admixtures, J. Mater. Civ. Eng. 2003, 15(2): 134-143.

[98] Monkman, Sean,, Shao, Yixin, Assessing the carbonation behavior of cementitious materials, J. Mater. Civ. Eng. 2006, 18(6): 768-776.

[99] Marlova P. Kulakowski, Fernanda M. Pereira, Denise C.C. Dal Molin Carbonationinduced reinforcement corrosion in silica fume concrete, Constr. Build. Mater. 2009, 23(3): 1189-1195. 


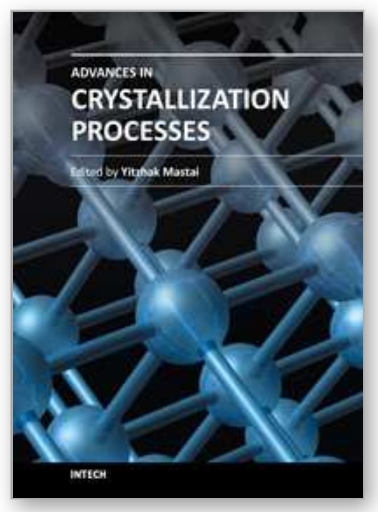

\section{Advances in Crystallization Processes}

Edited by Dr. Yitzhak Mastai

ISBN 978-953-51-0581-7

Hard cover, 648 pages

Publisher InTech

Published online 27, April, 2012

Published in print edition April, 2012

Crystallization is used at some stage in nearly all process industries as a method of production, purification or recovery of solid materials. In recent years, a number of new applications have also come to rely on crystallization processes such as the crystallization of nano and amorphous materials. The articles for this book have been contributed by the most respected researchers in this area and cover the frontier areas of research and developments in crystallization processes. Divided into five parts this book provides the latest research developments in many aspects of crystallization including: chiral crystallization, crystallization of nanomaterials and the crystallization of amorphous and glassy materials. This book is of interest to both fundamental research and also to practicing scientists and will prove invaluable to all chemical engineers and industrial chemists in the process industries as well as crystallization workers and students in industry and academia.

\section{How to reference}

In order to correctly reference this scholarly work, feel free to copy and paste the following:

Zanqun Liu, Geert De Schutter, Dehua Deng and Zhiwu Yu (2012). "Salt Weathering" Distress on Concrete by Sulfates?, Advances in Crystallization Processes, Dr. Yitzhak Mastai (Ed.), ISBN: 978-953-51-0581-7, InTech, Available from: http://www.intechopen.com/books/advances-in-crystallization-processes/salt-weatheringdistress-on-concrete-by-sulfates

\section{INTECH}

open science | open minds

\section{InTech Europe}

University Campus STeP Ri

Slavka Krautzeka 83/A

51000 Rijeka, Croatia

Phone: +385 (51) 770447

Fax: +385 (51) 686166

www.intechopen.com

\section{InTech China}

Unit 405, Office Block, Hotel Equatorial Shanghai

No.65, Yan An Road (West), Shanghai, 200040, China 中国上海市延安西路65号上海国际贵都大饭店办公楼 405 单元

Phone: +86-21-62489820

Fax: $+86-21-62489821$ 
(C) 2012 The Author(s). Licensee IntechOpen. This is an open access article distributed under the terms of the Creative Commons Attribution 3.0 License, which permits unrestricted use, distribution, and reproduction in any medium, provided the original work is properly cited. 